NBER WORKING PAPER SERIES

\title{
HEALTH INSURANCE, TREATMENT AND OUTCOMES: USING AUTO ACCIDENTS AS HEALTH SHOCKS
}

\author{
Joseph J. Doyle Jr. \\ Working Paper 11099 \\ http://www.nber.org/papers/w11099 \\ NATIONAL BUREAU OF ECONOMIC RESEARCH \\ 1050 Massachusetts Avenue \\ Cambridge, MA 02138 \\ February 2005
}

The views expressed herein are those of the author(s) and do not necessarily reflect the views of the National Bureau of Economic Research.

(C) 2005 by Joseph J. Doyle Jr.. All rights reserved. Short sections of text, not to exceed two paragraphs, may be quoted without explicit permission provided that full credit, including (C) notice, is given to the source. 
Health Insurance, Treatment and Outcomes: Using Auto Accidents as Health Shocks Joseph J. Doyle Jr.

NBER Working Paper No. 11099

February 2005

JEL No. I11

\begin{abstract}
$\underline{\text { ABSTRACT }}$
Previous studies find that the uninsured receive less health care than the insured, yet differences in health outcomes have rarely been studied. In addition, selection bias may partly explain the difference in care received. This paper focuses on an unexpected health shock - severe automobile accidents where victims have little choice but to visit a hospital. Another innovation is the use of a comparison group that is similar to the uninsured: those who have private health insurance but do not have automobile insurance. The medically uninsured are found to receive twenty percent less care and have a substantially higher mortality rate.
\end{abstract}

Joseph J. Doyle Jr.

MIT Sloan School of Management

50 Memorial Drive

Cambridge, MA 02142

and NBER

jjdoyle@mit.edu 


\section{Introduction}

Efforts to reform the $\$ 1.3$ trillion U.S. healthcare industry are often motivated by a concern that the uninsured are denied access to health care (NCHS, 2002). Indeed, theory suggests that health care providers would offer less treatment to the uninsured if they are less likely to pay for care. Previous empirical work supports this conclusion and finds that the uninsured receive approximately forty percent less health care than the insured. ${ }^{1}$

While treatment differences have been labeled the 'access gap', they can be difficult to interpret. First, health outcomes are rarely compared. Without knowing the effect on health, treatment differences may imply that the insured receive too much care, as opposed to the uninsured receiving too little. For example, moral hazard problems may allow physicians to practice what has been labeled 'flat-of-the-curve medicine', where diminishing returns to health care imply that additional treatment may yield small gains in terms of health outcomes (Enthoven, 1980). While the insured may receive more treatment, this may not translate into health differences.

Further, there may be selection problems. Individuals decide to purchase insurance and they decide to seek medical care. If those with a low risk of using medical care are also less likely to purchase insurance, then treatment differences may have little to do with access to care. This positive correlation between risk level and insurance coverage is a standard result in contract theory and suggests that information problems in insurance markets may lead to treatment differences. The empirical work is further complicated by the lack of an adequate comparison group to test whether unobserved differences between the insured and uninsured drive the difference in care received. 
To examine health outcomes and deal with selection problems, this paper focuses on an unexpected health shock - severe automobile accidents where incapacitated crash victims have little choice but to use professional medical care. Using a unique data set that links police accident reports to hospital discharge records, treatment levels and mortality rates are compared between the insured and uninsured. These data provide a complete picture of each accident and offer a new way to investigate whether the uninsured are denied access to life-saving health care. One innovation in the paper is the use of a comparison group that is similar to the uninsured in terms of risk-taking behavior, income, and vehicle characteristics: drivers who have health insurance but do not have automobile insurance.

The focus on severe automobile accidents has a number of advantages. First, police record thirty-day mortality — whether the victim dies within thirty days of the accident. This allows a comparison of health outcomes that are rarely studied (Levy and Meltzer, 2001). The few studies that have looked at inpatient outcomes find mixed evidence of insurance effects (Ayanian et.al. (1993), Currie \& Gruber (1997), Haas and Goldman (1994), Hadley et. al. (1991), Sada et.al. (1998)). ${ }^{2}$ These papers do not always control for differences in the illnesses suffered by the uninsured, while others rely on composite measures of physician diagnoses and procedures to control for illness severity. Such measures will depend on insurance status if the uninsured were offered less care. In contrast, this paper uses more objective severity measures

\footnotetext{
${ }^{1}$ Estimates center around forty percent less care for the uninsured. See, for example, Currie \& Gruber (1997), Currie and Thomas (1995), Haas and Goldman (1994), Long, Marquis, and Rodgers (1997), Spillman (1992), and Tilford et. al. (1999). Marquis and Long (1994) and Brown (1998) offer reviews.

${ }^{2}$ There is also a literature dealing with moral hazard problems in Workers Compensation, where benefit generosity has been found to be associated with longer work absences (Dionne and St-Michel, 1991; Fortin and Lanoie, 1992). These papers are able to exploit changes in insurance laws. Moral hazard problems stem from the subjects' choice to return to work, choice of physician, and even choice of injury (e.g. back pain), while the present study focuses on cases where demand is relatively inelastic — especially for individual diagnoses discussed below.
} 
such as police-reported injuries and crash characteristics. ${ }^{3}$ In addition, while previous papers did not control for differences in the hospitals used by the insured and uninsured, this paper exploits within-hospital variation in treatment and outcomes to explicitly control for hospital characteristics that do not vary across patients, such as hospital resources and accounting procedures.

Second, contact with professional health care providers is virtually automatic for severe accidents, as ambulances arrive as part of the crash investigation. The RAND Health Insurance Experiment dealt with selection bias by randomizing families to health plans (Newhouse, 1993) and found that participants with more generous health insurance consumed more health care. This paper focuses on a case where demand is inelastic to overcome the selection bias, as incapacitated victims have on the roadway have little choice but to receive some care. In contrast, the uninsured may not seek care for other health problems due to underlying differences in health risks or preferences that also contribute to their decision not to purchase insurance. In addition, previous papers were unable to control for the time patients wait to visit the hospital. The focus on severe crashes allows a comparison of treatment and outcomes from the moment the health problem begins.

Third, severe accidents are largely unexpected at the time of the health insurance purchase decision, as opposed to the chronic conditions that are usually studied (Brown, 1998). Patients live with chronic health problems and gain private information about future health care use. These are cases where adverse selection problems are at their most extreme, as those likely to use health care may be more likely to purchase insurance. This selection into insurance based on the unobserved propensity to use health care confounds the interpretation of treatment

\footnotetext{
${ }^{3}$ Haas and Goldman (1994) also study emergency care. However, they include all types of emergency care, and it appears that the case mix is substantially different between the insured and uninsured in ways that are not controlled.
} 
differences. If the decision to purchase insurance were not based on the likelihood of being in a severe automobile accident, then the approach taken here would largely avoid this selection problem.

Finally, automobile accidents are a particularly important health problem for the uninsured. Most health problems are common to older individuals who are almost universally insured. In contrast, the uninsured tend to be younger, and automobile accidents are the leading cause of death among those under the age of thirty-five (CDC, 1998).

The results suggest that the uninsured receive twenty percent less treatment than the privately insured, controlling for personal, crash, vehicle, neighborhood, and hospital characteristics. While this represents a substantial difference, it is smaller than the previous findings, suggesting that selection bias may be important. The uninsured are also found to have a higher mortality rate — an increase of 1.4 percentage points from the mean mortality rate of $3.8 \%$.

While the paper attempts to overcome selection bias at the time of the health problem, the uninsured likely differ from the insured in a number of ways that can affect the interpretation of the results. Much of the paper discusses tests which suggest that unobserved differences between the insured and uninsured do not drive the main results. For example, drivers who do not have automobile insurance have similar observable characteristics compared to the uninsured, yet automobile insurance status does not predict treatment or health differences.

The structure of the paper is as follows. Section two briefly presents theoretical considerations and their implications for interpreting the results. Section three describes the data and presents mean comparisons of treatment, mortality, and crash characteristics between the insured and uninsured. Section four presents empirical estimates where within-hospital variation

In addition, the paper does not control for differences in hospital characteristics and times-to-diagnosis. 
is used to test the effect of insurance status on treatment and mortality. Differences across hospital types are also discussed. Section five demonstrates the robustness of the results. Section six discusses implications of the findings, and section seven concludes.

\section{Theory}

At the time of an accident, insurance lowers the price of health care faced by the insured and raises the effective price that providers can collect. Both factors suggest that the insured will receive more treatment. The overall effect of insurance on treatment decisions, and ultimately health outcomes, is a combination of these supply and demand factors. However, when previous estimates compared treatment levels between the insured and uninsured, they may have overstated the insurance effect. In particular, the demand for insurance suggests that the insured may differ from the uninsured.

\section{Demand-side}

Consider first the demand for insurance. Those with a high risk of using health care may be more likely to purchase insurance. This positive correlation between risk and insurance coverage, due to adverse selection and/or moral hazard problems, is a standard result from contract theory (Chiappori and Salanie, 2000; Chiappori et. al. 2001). For example, consider a simple two-period model of insurance demand where there are two states of the world in the second period: healthy and sick. Further, consider two types of consumers categorized by their probability of becoming sick. In the first period, they maximize expected utility and can use market insurance to allocate resources to different states of the world. These models suggest that if insurance premiums were actuarially fair, then risk-averse consumers would fully insure. However, due to information problems, or other frictions, insurance premiums may not be 
actuarially fair. One way for insurance companies to overcome information problems is to price insurance packages, comprised of different deductible and co-payment combinations, in such a way that the choice of a particular package reveals the type of consumer: a separating equilibrium. It can be shown that in this environment only the most likely to suffer the sick state will be fully insured (Rothschild and Stiglitz, 1976). Chiappori et. al. (2001) generalized this result of a positive correlation between risk and insurance to a number of environments, including the co-existence of moral hazard and asymmetric information problems.

Agents will also differ with respect to tastes and income. Perhaps the most interesting difference for this current study is that individuals with a relatively high degree of risk aversion may be more likely to both purchase insurance and drive safely (de Meza and Web, 2001; Jullien, Salanie, and Salanie, 1999). While this is not a general result, it suggests the potential for a negative correlation between insurance coverage and health risk if safer drivers sustained less severe injuries. The potential for heterogeneity in risk preference is considered below.

Further, the demand for health care will depend on insurance status. Those with insurance face a lower price for health care at the time of an illness - only a deductible and copayment. This implies that they will be more likely to visit a doctor once ill, all else equal. One caveat is that by the time the uninsured do visit a hospital, their illnesses may be more severe. Previous work has estimated the probability that an individual will make a "health care contact" multiplied by the difference in treatment once contact has been made. In the cases studied here, the decision to visit the hospital is largely out of the control of the patient, as police or witnesses call for medical professionals.

\section{Supply-side}


The effect of reimbursement rules on treatment decisions has received considerable attention, begun by McGuire and Ellis (1986). Treatment decisions by health care providers are modeled, abstracting from the decisions of patients. Physicians choose treatment levels to maximize an objective function that includes both profits and the benefits of treatment to patients. The model suggests that an increased ability-to-pay, through insurance for example, would result in greater treatment. This is partially due to moral hazard problems in this insurance market, though it does not depend on profits being part of the objective function. If profits were incorporated into a resource constraint, where greater treatment of insured patients provides resources to treat both insured and uninsured patients, then the prediction of more treatment for the insured would remain.

Another factor affecting the supply response is whether insurance status is in the provider's information set at the time treatment decisions are made. In fact, it appears that one of the first pieces of information discovered is insurance status. Medical professionals search patients to find not only insurance information, but medical and emergency contact information as well. Insurance companies regularly recommend that consumers carry their insurance card especially for this type of situation. Once known, the expected payer is reported on the patient's chart. When treatment decisions are made, insurance status is likely known.

Finally, treatment differences may be smaller given the legal ramifications of refusing to treat patients. For example, federal law mandates that hospitals stabilize trauma patients. However, treatment differences after stabilization are predicted.

\section{Welfare implications}

Both supply and demand factors tend to suggest that the insured will receive more treatment. However, the welfare implications are less straightforward. Treatment differences 
may be efficient in a number of environments. For example, the uninsured may not value additional treatment as much as the insured, as suggested by the choice to purchase insurance. Consider the standard planner's problem where each person is weighted equally. The optimal consumption profile is such that the marginal utility of consumption is equated across individuals. In models of insurance demand, those who expect a higher marginal utility of consumption when sick are more likely to purchase insurance. If the insured had a higher marginal utility of consumption when sick, then the insured would require greater treatment levels to equate marginal utilities.

One case where inefficiencies are more easily tested is the case of overutilization by the insured. Consider a health production function that maps treatment into health benefits. It has been argued that at the advanced state of technology in the U.S., diminishing returns have resulted in physicians practicing 'flat-of-the-curve' medicine. That is, the insured may receive more care, but it may have little effect on health outcomes. In this case, the marginal benefit of treatment is close to zero, which is less than the positive marginal cost, and welfare implications stem from distorted insurance prices. However, if the additional treatment received by the insured were useful in improving patient outcomes, then observed differences in treatment may represent underutilization by the uninsured, overutilization by the insured, or both.

Supply and demand factors largely suggest that the uninsured will receive less treatment. If health were increasing in treatment, conditional on injury severity, then the insured would have better outcomes as well. However, if a positive correlation between risk and insurance coverage were due to private information problems in insurance markets, then self-selection into insurance markets would contaminate treatment and health outcome comparisons (Heckman, Lalonde, and Smith, 1999). As opposed to the chronic conditions usually studied, where private 
information problems are likely at their most extreme, this paper conditions on an unexpected health shock to mitigate the effect of this selection problem.

\section{Data Description}

The Crash Outcome Data Evaluation System (CODES) offers a unique data set to compare patients following an automobile accident. CODES links police accident reports with hospital discharge records using identifiers such as patient name, birth date, and time of accident. The National Highway Traffic Safety Administration subsidized individual state efforts to link these two sources of data, and, until now, they have only been used to study highway safety (NCSA, 1998).

This paper uses data from Wisconsin for the period 1992 through $1997 .{ }^{4}$ In Wisconsin, all police accident reports are submitted to the Wisconsin Department of Transportation, and all inpatient hospital records are submitted to the Wisconsin Department of Health and Family Services. Analysts at the Center for Health Systems Research and Analysis (CHSRA), located at the University of Wisconsin at Madison, linked these data in an effort to improve traffic safety research.

According to CHSRA, approximately $80 \%$ of all crash-related hospitalizations were linked successfully. Crash victims who die at the scene of the accident are not present in the inpatient data, so it is not possible to identify the health insurance status of these victims. As a

result, mortality comparisons are done after patients reach the hospital. Other reasons for linkage failure include the following: the patient was transported out of Wisconsin, the crash was not reported to the police, or the crash record contained insufficient identifying information. For the 
severe accidents investigated here, the proportion of matches is likely to be even higher than $80 \%$. For example, severe crashes are more likely to be reported and identifying information, such as the time of the accident, is more likely to be known for ambulance transfers. While difficult to test here, CHSRA data documentation argues that "there is no reason to expect that the cases not linking are different from cases which do link."

\section{Police Measures}

The police-report data offer a complete picture of each accident. Characteristics such as age, sex, ZIP code of residence, seat location, seat belt use, entrapment in the vehicle, and injury severity are available. Wisconsin Police report injury severity according to the KABCO score: Killed; A, B, or C injuries consisting of incapacitating injuries, non-incapacitating injuries, or possible injuries; and other or unknown. At the accident scene, a police officer records the injury category. If the crash victim later died due to the accident, then the injury severity was scored as a K—even if the death occurred after hospital discharge. ${ }^{5}$ Other crash characteristics include vehicle damage, road condition, population size where the accident occurred, and the types of crashes, vehicles, and roads.

The police also record the Vehicle Identification Number (VIN) for crash victims in cars and trucks. These VINs were decoded by Primedia Price Digests ${ }^{6}$ to categorize vehicles by engine size, manufacturer's suggested retail price, two-door status, vehicle weight, and model

\footnotetext{
${ }^{4}$ Wisconsin is one of the original CODES states and the only state that regularly supplies a public-use data set. All 23 CODES states were contacted. Most of the other states are still in the process of linking the data or did not have key variables of interest.

${ }^{5}$ The scores of K are the raw data for the often-used Fatality Analysis Reporting System (FARS) distributed by the National Highway Traffic Safety Administration. It is generally regarded as 'thirty-day mortality' meaning that deaths up to thirty days from the accident are recorded in the police data, though deaths after thirty days are also recorded. For a small number of cases the patient died in the hospital and the KABCO score does not equal K. These have been coded as fatal injuries in the analysis, though results are not sensitive to this definition. As noted above, those who die at the scene do not enter the inpatient data. The severity of injury at the time of entry into the hospital is explored more fully below.

${ }^{6}$ A Unit of Primedia Business.
} 
year. The size of the car can affect injury severity, while the quality of the car serves as a proxy for socio-economic status.

The ZIP code of residence is also included in the report, as well as the hospital discharge data. This information allows a comparison of neighborhood characteristics such as the fraction of the population in poverty, race categories, educational categories, and median household income, available from the 1990 US Census. $^{7}$ If patients from wealthier backgrounds receive favorable treatment and are more likely to have insurance, then controlling for these neighborhood characteristics provides a way to isolate the effect of insurance on treatment and health outcomes.

The linked police data provide a novel comparison group: drivers who have health insurance but do not have automobile insurance. This information is recorded because it is illegal to drive a vehicle in Wisconsin without having such insurance. Those who do not have automobile insurance have revealed that they take risks by forgoing the insurance, and they have similar observable characteristics to the patients who do not have health insurance in terms of their vehicles, neighborhoods, and crash types.

Police-reported crash and personal characteristics offer a new way to control for injury severity. The police measures are less likely to be influenced by the victim's health insurance status compared to diagnoses of health care providers. This paper attempts to control for injury severity by comparing patients who were in similar accidents. For example, a patient who crashed on a rural highway resulting in severe vehicle damage will have greater injuries compared to a patient who crashed on a slower moving urban street. Of course, hospital data can be used to supplement the police measures of injury severity. 


\section{Hospital Measures}

The hospital discharge data also provide a rich set of variables. These also include age, sex, and measures of treatment, such as total facility charges and length of stay, and codes for procedures and diagnoses. The total facility charges represent the standard room and procedure charges as opposed to the amount billed to insurance companies or the government. This is particularly useful for research purposes, as charges are uniform across insurance plans within each hospital. Major diagnostic categories are used to compare patients with similar types of injury, such as nervous system or musculoskeletal injuries.

Finally, the expected payer is reported. As in previous work, "uninsured" is defined as having the expected payer identified as self-pay as opposed to a form of private insurance or government program. While the uninsured may be partially insured through subsequent lawsuits or through automobile insurance, these are uncertain payments that hospitals do not look to first. The hospital would have to judge the probability that another driver caused the accident times the probability that the other driver has liability insurance, in which case the hospital may receive payment much later. ${ }^{8}$ In addition, medical insurance within automobile insurance contracts is usually capped at a low payment level, such as $\$ 2500$ - far below the costs of care in these severe crashes. Meanwhile, the patients chart will note the lack of insurance as opposed to any partial coverage afforded to crash victims. It appears, then, that hospitals would regard the uninsured as likely candidates for uncompensated care, while the partial coverage will make finding treatment differences for the uninsured more difficult.

\footnotetext{
${ }^{7}$ The use of ZIP code fixed effects is also explored below. Restricting the analysis to within-ZIP, within-hospital variation may be too restrictive in identifying mortality effects. Nevertheless, similar results are found when ZIP code fixed effects are included.

${ }^{8}$ Much of hospital bad debt is due to catastrophic events to uninsured patients, suggesting they often do not get paid. In addition, Wisconsin is not a no-fault insurance state. That is, reimbursement from an insurance company would require proving that another driver was at fault. Also, at the time of these crashes, Wisconsin was one of the few states that did not require automobile policies to include liability insurance.
} 
The total number of linked police-hospital records is 28,236 and ten percent are

uninsured. This fraction is similar to the estimated $9-11 \%$ of the non-elderly population who are uninsured in Wisconsin over this period (KFF, 1998). The sample is restricted in a number of ways to provide more meaningful estimates of treatment and mortality differences, though results are similar when the entire data set is used as shown below. First, to consider patients who are the least likely to make treatment decisions, the estimation focuses on the most severely injured patients: those who were judged by the police to be incapacitated and those who eventually died. ${ }^{9}$ This results in 16,648 observations. Patients over the age of sixty-five are excluded due to near universal insurance coverage through Medicare. Also, hospital records are available for patients where they were finally discharged, so patients who transferred from another hospital will mechanically have shorter lengths of stay. These observations are dropped for comparability, though insurance status does not predict hospital transfer. ${ }^{10}$ It does not appear that hospitals transfer the financial risk of treating uninsured patients to other hospitals. Finally, comparisons are first restricted to the uninsured and the privately insured. Comparisons with Medicaid recipients are made separately. These restrictions result in 10,842 patients to study, of which nearly fifteen percent are uninsured. ${ }^{11}$

Table 1 shows the basic results in the form of a mean comparison. The top panel compares the uninsured with the privately insured, while the bottom panel compares medically

\footnotetext{
${ }^{9}$ According to the National Safety Council's 1996 Manual on Classification of Motor Vehicle Traffic Accidents, an incapacitating injury is "any injury, other than a fatal injury, which prevents the injured person from walking, driving or normally continuing the activities the person was capable of performing before the injury occurred. Inclusions: severe lacerations, broken or distorted limbs, skull or chest injuries, abdominal injuries, unconsciousness at or when taken from the accident scene, and unable to leave the accident scene without assistance, and others. Exclusion: momentary unconsciousness". It appears that almost all of those with fatal injuries were incapacitated at the scene as evidenced by their nearly universal rate of ambulance transfer.

${ }^{10} 5.7 \%$ of the incapacitated crash victims were transferred. In a regression predicting hospital transfer with full controls, an indicator of having health insurance has a coefficient of -0.004 with a standard error of 0.005 .

${ }^{11}$ The restrictions dropped 2,113 observations due to age. 804 observations were dropped due to transfer. There were 2,065 observations where the patient has Medicaid or other government insurance. Medicaid recipients will be
} 
uninsured drivers to those with private health insurance but no automobile insurance - a group similar on observable characteristics. In both comparisons, the uninsured receive less treatment and have higher mortality, on average. For example, the uninsured stay in the hospital for 6.4 days, compared to 9.2 days for the insured - a thirty percent difference. Similarly, average facility charges are $\$ 13,100$ versus $\$ 20,700$. Median differences are smaller, though still substantial: 4 days in care for the uninsured and 5 days for the insured, while the median facility charges are $\$ 6,700$ compared with $\$ 8,900 .^{12}$ The uninsured have higher mortality rates in the raw data as well, $4.4 \%$ vs. $3.7 \%$.

The predicted mortality is also reported, as a first look at injury severity. This is the average predicted value from a regression of mortality on all of the police and hospital measures used in the paper (with the exception of insurance status). Based on these observables, and the assumption that the effect of these regressors on mortality is homogeneous across the two groups, it does not appear that the uninsured are more likely to have fatal crash characteristics. ${ }^{13}$

Table 2 shows that these treatment differences remain within police-reported injury severity levels. The table also shows that total facility charges increase with injury severity, suggesting that police evaluations are informative. The difference in treatment is larger for more severely injured patients. Patients with possible or unknown injuries are more likely to choose whether to visit the hospital. Selection of the relatively healthy uninsured victims out of the hospital data may contribute to the smaller treatment differences found in these categories.

examined in section five. 717 observations were lost due to missing hour of day or major diagnostic code values, and 107 observations were dropped when all of the patients in a particular hospital were insured.

${ }^{12}$ As the median and mean comparison shows, the treatment measures are right skewed, as usual. In the panel regressions used below, the natural logarithm of each treatment measure is used to place less weight on the extreme observations. In addition, the results are shown to be robust to trimming the data of large and small observations.

${ }^{13}$ The standard deviation of predicted mortality is similar in the two groups, so heteroskedasticty due to the estimated nature of the predicted mortality should not affect the test of mean equivalence. In fact, the t-tests are identical when observations are weighted by the inverse of the square-root of the predicted mortality standard deviation. 
Alternatively, there may be less discretion in these types of cases, as they often involve broken bones that may require similar procedures for both the insured and uninsured.

\section{Differences between the Insured and Uninsured}

Incapacitation at the scene does not mean that patients will have similar observable characteristics. Indeed, if accidents were completely random, then the differences in the population, such as age or inclination to wear a seatbelt, would be revealed in the incapacitation sample. Much of the paper attempts to control for these differences, including the use of patients who do not have automobile insurance as a comparison group. The CODES data also provide a particularly rich set of control variables. Table 3 summarizes these controls and reveals some key differences between the two groups.

The uninsured are slightly younger ( 29 vs. 30 ) and more likely to be male ( $72 \%$ vs. $62 \%$ ). Perhaps surprisingly, they are less likely to substitute self-protection in the form of a restraint (a seat belt or child seat) compared to the insured (19\% vs. $30 \%)$, consistent with differences in seat belt use found by Clyde et.al. (1996). The uninsured are more likely to drive late at night (32\% vs. 24\%). They also drive older cars and come from poorer neighborhoods, consistent with the fact that the uninsured tend to be poorer than the privately insured. While these comparisons suggest that the uninsured may suffer more severe injuries, the uninsured are less likely to have a diagnosis of multiple significant trauma ( $16 \%$ vs. $20 \%)$, or to be trapped at the scene ( $15 \%$ vs. 17\%) —both predictors of mortality. ${ }^{14}$ Table 1 suggests that the predicted mortality for the uninsured is actually slightly less than the predicted morality for the privately insured.

\footnotetext{
${ }^{14}$ While the major diagnostic categories are used to compare patients with similar areas of injury, the smaller proportion of uninsured patients with multiple significant trauma may reflect less treatment received by the uninsured. The results are shown with and without these controls.
} 
There are some similarities between the two groups. Both groups come largely from rural areas. In addition, vehicle damage and vehicle types are also similar for the two groups.

\section{Empirical Model and Results}

The mean differences in treatment and mortality are suggestive that the uninsured receive less care. Conditioning on observable crash and personal characteristics provides a way to compare patients with similar injuries. Further, hospital fixed effects are used to exploit withinhospital variation in treatment. In this way, hospital characteristics that are constant across patients, such as accounting procedures, charity care policies, and trauma resources, are controlled. In addition, year indicators are included to control for unobservable characteristics that vary by year, such as technological advancement, but affect both the insured and uninsured. Mortality will be used to test the effect of insurance status on patient outcomes. A linear probability model is used where the dependent variable equals one if the patient died and zero otherwise, which facilitates the use of hospital and year fixed effects. ${ }^{15}$

For person $\mathrm{i}$ at hospital $\mathrm{h}$ in year $\mathrm{t}$, the estimating equations are:

$$
\begin{aligned}
& \ln \left(\text { Treatment }_{\text {iht }}\right)=\gamma_{0}+\gamma_{1} \text { Uninsured }_{\text {iht }}+\gamma_{2} \text { Personal Characteristics }_{\text {iht }} \\
& +\gamma_{3} \text { Crash Characteristics }_{\text {iht }}+\gamma_{4} \text { Vehicle Characteristics }_{\text {iht }} \\
& +\gamma_{5} \text { Neighborhood Characteristics }_{\text {iht }}+\theta_{h}+\delta_{t}+\varepsilon_{\text {iht }} \text {, } \\
& \text { and } \\
& \text { Fatal }_{i h t}=\phi_{0}+\phi_{1} \text { Uninsured }_{\text {iht }}+\phi_{2} \text { Personal Characteristics }_{\text {iht }} \\
& +\phi_{3} \text { Crash Characteristics }_{\text {iht }}+\phi_{4} \text { Vehicle Characteristics }_{\text {iht }} \\
& +\phi_{5} \text { Neighborhood Characteristics }_{i h t}+\eta_{h}+\lambda_{t}+v_{i h t}
\end{aligned}
$$

with the usual exogeneity assumptions: letting $\mathrm{Z}$ represent all right hand side variables,

$$
E\left(\varepsilon_{i h t} \mid Z\right)=E\left(v_{i h t} \mid Z\right)=0
$$


The natural log transformation of the treatment variables is standard in the literature, as these variables are right skewed. All personal and crash characteristics listed in Table 3 are used as controls, with the exception of airbag deployment, which was only available since $1995 .^{16}$ Given the wide range of ages in the data set, five age categories are included to allow a nonlinear relationship. Individual indicators for the hour of the day and day of the week are also included.

From the Vehicle Identification Number, model year indicators are included in the model, as well as the engine size, MSRP, vehicle weight, and two-door status indicators listed in Table 3. The VIN is recorded in $83 \%$ of car and truck crash victims ( $84 \%$ for privately insured and $79 \%$ for the uninsured). For observations with missing vehicle information, and for motorcyclists, bicyclists and pedestrians, the data have been filled with sample mean values and an indicator for missing VIN information is included. ${ }^{17}$ Similarly, for the two percent of the observations that came from ZIP codes where Census data have been suppressed due to small population sizes, an indicator for these observations has been included in the analysis. Results are similar when alternative specifications are used, as shown below.

\section{A. The Uninsured Receive Less Treatment}

Table 4 presents the main results where all of the models include hospital and year fixed effects. Panel A shows the estimates from the treatment regressions. Columns (1) and (6)

\footnotetext{
${ }^{15}$ The results are similar when probit models are estimated.

${ }^{16}$ In these severe crashes, the VIN is recorded in $83 \%$ of car and truck crash victims ( $84 \%$ for privately insured and $79 \%$ for the uninsured). For these cases and for motorcyclists, bicyclists, and pedestrians, the vehicle information has been filled in with sample mean values and an indicator for missing VIN information is included. A second indicator for is included for the subset of observations with all vehicle information except for vehicle weight. This is largely due to the older vehicles driven by the uninsured, controlled for in the analysis with model-year and calendar-year indicators. Similarly, for the two percent of the observations that came from ZIP codes where Census data have been suppressed due to small population sizes, an indicator for these observations has been included in the analysis.

${ }^{17} \mathrm{~A}$ second indicator is included for the subset of observations with all vehicle information except for vehicle weight. This is largely due to the older VINs not containing such information, which is controlled for in the analysis with model-year indicators.
} 
provide estimates from models that include an indicator for insurance status and no additional controls. The uninsured are found to receive fifteen log points fewer charges and twenty log points fewer days in care. These estimates are smaller than the insurance effects found in the mean comparisons of Table 1, which showed differences of thirty log points fewer facility charges and twenty-eight log points fewer days in care. This is partly due to the fact that the uninsured tend to be treated at hospitals that offer less treatment to everyone. It could be that the severity of crashes or hospital resources differ in areas where the uninsured live. This implies that it is important to consider the effect of hospital and local area characteristics when measuring treatment differences between the insured and uninsured. ${ }^{18}$

The remaining columns progressively add control variables and demonstrate the stability of the estimates. The inclusion of police crash measures and vehicle characteristics do not alter the estimated effect of insurance on treatment. The main results in Columns (4) and (9) include all of the control variables listed in Table 3, including controls for the five major diagnostic categories. While these categories are a function of treatment decisions, inclusion does not change the overall results and serves as an attempt to compare patients with similar types of injury. Total facility charges are approximately fourteen log points lower for the uninsured and length of stay is seventeen log points lower. An advantage of the relatively large sample of uninsured patients is that the estimates are fairly precisely estimated with standard errors of approximately 0.02 .

Re-transforming the estimates in columns (3) and (7) from log points to percentages, the uninsured are found to receive $22 \%$ fewer facility charges and $20 \%$ fewer days of care. ${ }^{19}$

\footnotetext{
${ }^{18}$ The smaller estimates may also be explained by the increased influence of measurement error in models with fixed-effects. However, this explanation is not consistent with the mortality results shown below.

${ }^{19}$ The natural logarithm of each treatment measure is used, as is standard in the health literature where the measures, such as length of stay in the hospital, are right skewed. When interpreting the estimates in terms of percentages or
} 
Evaluated at the sample mean of the control variables, this represents a difference of $\$ 3,300$ in facility charges and 1.8 days in care. ${ }^{20}$

Columns (5) and (10) introduce a categorical variable equal to one if the primary payer were a Health Maintenance Organization (HMO), with fee-for-service insurance as the omitted category. HMOs are associated with slightly less treatment, three log points fewer days in care and four log points fewer charges. The small difference is not surprising, as fee-for-service plans also contract with hospitals to monitor the care provided. Interestingly, Medicare often pays HMOs five percent less than fee-for-service arrangements - a difference in treatment similar to the one found here.

Other variables largely have the expected results as shown in the appendix. Older and rural patients receive more treatment, as do those who were in a head-on collision, suffered multiple significant trauma, or were trapped in their vehicle. Using a seatbelt or child safety seat is associated with less treatment, as expected from previous studies showing the importance of seatbelts in preventing injury. Occupants of vehicles with small engines, motor cycle riders and

dollars, as opposed to log points or log dollars, the results are re-transformed, and it is necessary to consider heteroskedasticity (Manning, 1998). Consider that the estimating equation

is: $\ln \mathrm{T}=\mathrm{X} \beta+\varepsilon$ or $T=\exp (X \beta) \exp (\varepsilon)$ and $E(T \mid X)=\exp (X \beta) E(\exp (\varepsilon))$. To compare the two groups, let $\beta_{1}$ be the coefficient associated with being uninsured and evaluate the expectations at common levels of the remaining right-hand-side variables, $\bar{X}_{-1}$ with associated coefficients $\beta_{-1}$. The ratio of expected treatment for the two groups is given by:

$$
\frac{E\left(T \mid \text { Uninsured }, \bar{X}_{-1}\right)}{E\left(T \mid \text { Insured }, \bar{X}_{-1}\right)}=\exp \left(\beta_{1}\right) * \frac{\exp \left(\bar{X}_{-1} \beta_{-1}\right)}{\exp \left(\bar{X}_{-1} \beta_{-1}\right)} * \frac{E(\exp (\varepsilon) \mid \text { Uninsured })}{E(\exp (\varepsilon) \mid \text { Insured })}=\exp \left(\beta_{1}\right) * \frac{E(\exp (\varepsilon) \mid \text { Uninsured })}{E(\exp (\varepsilon) \mid \text { Insured })}
$$

Note that because the remaining right hand side variables are evaluated at the same level, they cancel in the ratio. Also, by Jensen's inequality, the expectation of the exponentiated error is greater than the exponential of the expectation of the error. So both groups may have an error term with an expected value of zero, but that need not translate into the exponentiated error terms having the expected value of one. In practice, the expectations can be substituted by their sample counterparts--the average of the exponentiated residuals for the two groups--to form the nonparametric "smearing factor". The re-transformed estimate of the treatment gap is in percentage terms instead of $\beta_{1}$, which is in log points.

${ }^{20}$ In forming the nonparametric "smearing factor", the average exponentiated residuals in the charges regression are 1.44 for the uninsured and 1.61 for the insured. For length of stay, they are 1.36 and 1.43. The expected charges and length of stay for the insured are calculated to be $\$ 15,174$ and 9.0 days, evaluated at the sample mean of the control variables. 
pedestrians receive more treatment. Women tend to receive slightly less treatment as measured by facility charges, though they stay in care slightly longer.

\section{Differences in Procedures}

Analyzing individual procedures suggests that the uninsured received less treatment on a broad array of care. Considering the one hundred most frequent three-digit procedure codes used in these trauma cases, nineteen procedures were found to differ between the insured and uninsured (at a five-percent level of significance), in a model with full controls and hospital fixed effects. ${ }^{21}$ Of those nineteen, only "suture or other closure of skin" was greater among the uninsured. The uninsured received fewer spinal fusions, skeletal traction, and operations on the brain, kidney, bladder, chest, large intestine, vessels, and plastic surgery on the face, muscles, and tendons. They also received fewer diagnostic ultrasounds. Apart from these costly operations and tests, the uninsured received fewer amputations as well. When hospital fixed effects are removed from the models, 22 of the top 100 procedures show differences (at the fivepercent level), where two are greater for the uninsured: sutures and "alcohol and drug rehabilitation and detoxification." This again points to the potential differences between the two groups, though controlling for driving under the influence does not affect the main results. These procedure differences suggest that a lack of health insurance has had a significant effect on treatment decisions on a wide range of health problems, including potentially life saving procedures.

\section{B. Effect on Mortality}

Panel B of Table 4 shows the mortality results. Column (1) shows that the uninsured are associated with a 1.3 percentage point increase in mortality when only hospital and year fixed

\footnotetext{
${ }^{21}$ The mean number of observations for the 100 comparisons is 83 , the median is 19 , the minimum is 6 and the maximum is 1622 .
} 
effects are included. This result is stable to the addition of control variables as shown in columns (2)-(4). Column (4) shows the result using all of the control variables, and the uninsured have higher mortality by 1.5 percentage points - thirty-nine percent higher than the sample mortality rate of 3.8\%. Finally, HMOs and fee-for-service insurance plans have similar mortality rates, which is not surprising given the small difference in treatment between HMOs and fee-forservice insurance plans.

Other variables again have expected effects as shown in the appendix. For example, wearing a seatbelt reduces the risk of death, while an increased risk of death is associated with suffering multiple significant trauma or being trapped in a vehicle.

The use of hospital fixed effects strengthens the mortality result slightly. In models without fixed effects but with all other controls, the coefficient on being uninsured is 0.012 with standard error of 0.006. The larger estimates with hospital fixed effects argue against the increased influence of measurement error as an explanation for the smaller treatment differences found when hospital fixed effects were introduced. This larger mortality result is partly due to the fact that the uninsured tend to have greater mortality differences in hospitals that serve fewer uninsured patients. These hospitals may face smaller subsidies for providing charity care to the uninsured, possibly resulting in less care and higher mortality. The insured may live closer to hospitals that have greater resources, where mortality differences are more likely to be evident. Again, it is important to consider hospital differences when comparing the insured and uninsured.

\section{Comparison of Hospital Types}

The 1992 Wisconsin Hospital Fiscal Survey and the 1992 Annual Survey of Hospitals conducted by the Wisconsin Bureau of Health Information provide detailed information on 
hospital resources, usage of charity care and bad debt expenses, teaching status, and mission. Hospitals that vary by resources, "generosity", or mission may treat the uninsured differently. Table 5 shows the results of regressions that restrict the sample to particular types of hospitals.

First, whether more generous hospitals provide more care is tested. The measures of generosity are the fraction of total revenue forgone to charity care, and the fraction of total expenses coming from writing-off bad debt. A higher bad-debt expense ratio may imply less strict collection policies. One check on the hospital surveys is that hospitals with greater-thanmedian bad-debt ratios are found to serve more uninsured patients. Nevertheless, the treatment and mortality differences at generous hospitals are found to be similar to the main results.

Second, the resources available to the hospital may influence treatment decisions. Resources are measured by the hospital's return on assets in 1992, the number of intensive-careunit beds, and income from public sources which may imply access to public money or that the hospital requires more support. The sample was divided into two groups based on the median hospital's resources. Table 5 shows that hospitals with more intensive-care-unit beds and higher returns on assets have slightly larger treatment differences. Meanwhile, restricting the data to hospitals with greater than median income from public sources shows similar treatment differences and greater mortality differences. These hospitals have the greatest potential to perform costly, life saving procedures. The mortality rate is higher at these hospitals as the most serious cases may be delivered there. It is not surprising, then, that the difference in treatment and mortality are more evident in these hospitals.

Another estimate of resources available is teaching status. There are six teaching hospitals in Wisconsin, which typically have more advanced technology. That said, young physicians are learning their craft, and anecdotal evidence suggests that the uninsured may 
receive more care from inexperienced physicians. The results suggest that treatment and mortality differences are much larger at teaching hospitals compared to non-teaching hospitals. Again, hospitals with more resources may have the ability to provide costly, life-saving care to the insured.

The last category is hospital mission. Nonprofit hospitals that are religiously affiliated are compared to those that are not. This tests whether manager motivations affect the provision of care. ${ }^{22}$ Patients at the two types of hospitals are similar, with religious hospitals more likely to have rural patients ( $80 \%$ vs. $77 \%)$. In the non-religiously-affiliated hospitals, where most of the data reside, show results similar to the full sample. In the subset of hospitals that are religiously-affiliated, treatment differences are smaller and the mortality result goes away. In fact, the sign of the effect of no insurance on mortality becomes negative. When the sample size changes this drastically, the mortality result is more volatile and this result should be interpreted with caution. Nevertheless, it suggests that such hospitals provide more care to the uninsured than hospitals that are not religiously affiliated.

One issue that arises is the selection of hospital by the patient or ambulance driver. With the most severe crashes, patients are supposed to be taken to the nearest hospital that can accommodate trauma cases. The uninsured do tend to go to hospitals with fewer resources, which may be due to the location distribution of accidents. One example is that $10 \%$ of the teaching hospital patients are uninsured (matching the average for the state), while $16 \%$ of the non-teaching hospital patients are uninsured. If the only uninsured patients that go to teaching hospitals are the worst off, explaining the mortality result, then we would expect them to receive more treatment in general, not less. On the other hand, the uninsured patients who go to teaching 
hospitals may be those who live nearby, whereas the insured patients must travel longer to arrive. This may offer an explanation of the treatment differences, but not the mortality difference. A more complete discussion of the potential for unobserved differences in injury severity and timeto-hospital is discussed in the next section.

\section{Specification and Robustness Tests}

Provider sensitivity to insurance status has been offered as an explanation for the lower treatment levels and higher mortality rates among the uninsured. Alternatively, a number of unobserved characteristics may explain the results. This section presents a number of specification and robustness tests, and the results suggest that unobserved heterogeneity in injuries, crash types, and personal characteristics do not drive the treatment and mortality differences.

\section{No Health Insurance vs. No Automobile Insurance}

According to the mean comparisons in Table 3, the uninsured tend to be riskier drivers, come from poorer neighborhoods, and drive older, less expensive vehicles. These differences suggest that the uninsured may have worse health problems in ways that are difficult to control.

One way to test the effect of these unobserved differences is to match the uninsured with a similar group of patients. The linked police data provide a novel comparison group: drivers who have health insurance but do not have automobile insurance. These drivers have revealed that they take more risks by forgoing insurance. Table 6 shows that they are similar to the medically uninsured in terms of age, sex, time and day of the accident, and major diagnosis codes. In this driver subset, two additional variables are also similar between the groups: an

\footnotetext{
${ }^{22}$ Nearly all of the hospitals in the data are not-for-profit, precluding the usual comparisons of public vs. private and for-profit vs. nonprofit (Duggan, 2000; Norton and Staiger; 1994, Sloan, 1999). The only public hospital closed in
} 
indicator for driving under the influence of alcohol ( $38 \%$ vs. $42 \%)$, and an indicator that the driver was at least partially at fault (72\% vs. $77 \%)$.

The two groups also come from similar neighborhoods. While the neighborhoods where the medically uninsured live differ from those with private health insurance, Table 6 shows that the race, education, and income measures are close between the two groups. Car and truck characteristics are also similar, with the exception that the medically uninsured are more likely to driver newer cars (19\% vs. $9 \%)$.

The biggest difference in the two groups is the likelihood of driving a motorcycle ( $24 \%$ vs. $42 \%$ ). Those without auto insurance also tend to come from larger cities and are less likely to wear a seatbelt. Results are not sensitive to considering drivers of cars and trucks only, drivers in smaller towns, or drivers not wearing a seatbelt as shown below.

Table 7 shows the results of regressions similar to the main results. ${ }^{23}$ The medically uninsured are found to receive fifteen log points fewer charges, nineteen log points fewer days in care, and have a 1.7 percentage point higher mortality rate. Given the similarity in observable characteristics, it appears that differences such as income level, vehicle quality, or risk taking behavior are not driving the main results.

\section{Further Specification Tests}

Table 8 shows the results of further specification tests. The first set considers patients who have private health insurance and tests whether automobile insurance status affects treatment and mortality. The main results regress treatment and mortality on an indicator that the patient was uninsured. If having no insurance were a proxy for some other cause of the treatment and mortality differences, then the automobile insurance indicator may predict some

1995 (other than the University of Wisconsin's teaching hospital), and there are no for-profit hospitals in these data. 
difference in treatment and mortality. Table 8 shows that automobile insurance is not related to treatment or mortality, suggesting that the ability-to-pay of patients is driving the earlier results — not risk preference or income differences between the medically insured and uninsured. $^{24}$

\section{Accident-level fixed effects}

Another consideration is that the uninsured may get into crashes that are different in ways that are not controlled in the above regressions. For example, the uninsured may be more likely to crash far from a hospital and the longer travel time may explain the mortality result. ${ }^{25}$ Table 8 reports results for the 113 accidents where at least one uninsured and one insured patient were deemed incapacitated and visited the same hospital. The treatment and mortality regressions were estimated with accident-times-hospital fixed effects, though alternative specifications were similar. $^{26}$ The results are remarkably consistent with the estimates using the larger sample: twelve log points fewer charges, seventeen log points fewer days in care, and a 1.4 percentage point higher mortality rate. Of course, these estimates are measured with less precision due to the smaller sample sizes, but the similarity in the point estimates supports the robustness of the results.

\footnotetext{
${ }^{23}$ In models comparing all drivers, the results are similar, and the inclusion of an indicator of having automobile insurance, driving under the influence, and being at fault do not change the estimates.

${ }^{24}$ Analysis was also conducted considering only those who do not have automobile insurance- a smaller sample of 1192 patients of which $30 \%$ are medically uninsured. The two groups are similar in terms of seat belt use and areas of injury, while the uninsured still tend to come from smaller cities and are less likely to ride a motorcycle. Similar results are found with the medically uninsured receiving $21 \log$ points fewer charges with a standard error of 0.064 and $24 \log$ points fewer days in care with a standard error of 0.057 . They also have a mortality rate that is 0.083 percentage points higher (standard error 0.011) - again a large difference given the sample average of 2.0 percent, though it is less precisely estimated.

${ }^{25}$ Time to the hospital is not available in the data. However, introducing county-of-accident fixed effects to control for cross-county admissions has no effect on the coefficients.

${ }^{26}$ Another 68 accidents occurred with incapacitated insured and uninsured occupants who were delivered to different hospitals. Incorporating these accidents in models with accident fixed effects, but no hospital fixed effects, the coefficients (standard errors) on charges, length of stay, and mortality are $-0.14(0.10),-.20(.09)$, and .010 (.02) respectively. Including hospital fixed effects yields estimates of $-0.08(0.12),-0.16(0.10)$, and $0.015(0.03)$, respectively.
} 


\section{Comparison of Injury Severity}

Results shown in Table 8 suggest that unobserved differences in injury severity do not drive the treatment and mortality results. First, insurance status does not predict police-reported injury severity. Using the full sample of survivors, a linear probability model was estimated with the dependent variable equal to one if police report that the patient were incapacitated and zero otherwise. The full set of controls and hospital and year fixed effects are also included. Table 8 shows that being uninsured is not associated with incapacitation at the scene. Another test focuses on the use of an ambulance. If the uninsured were more likely to refuse to travel by ambulance and arrive later to the hospital, they may be lost from the sample or have systematically different injuries. Table 8 shows that insurance status does not predict whether the patient uses an ambulance.

One way that the uninsured can affect injury severity is the way they drive. This would explain the treatment differences if the uninsured succeeded in avoiding the most severe accidents, while it would explain the mortality result if they had more severe accidents. One way to abstract from the effect of driving quality is to examine passengers only. While uninsured passengers may be similar to drivers due to positive assortative "mating", they have less control over the likelihood of an accident. Table 8 shows that the results are similar for the subset of passengers.

These tests suggest that the uninsured are not likely to have different levels of injury severity. This is also suggested by the finding that the uninsured receive less treatment yet die more often. For example, the mortality difference may be due to more severe injuries suffered by the uninsured, as suggested by their disproportionate representation in the incapacitation sample, their apparent risk taking behavior of not wearing a seatbelt, and their older, potentially 
less safe, cars compared to the privately insured. However, if they had more severe injuries, more treatment should have been observed for survivors, not less. Alternatively, less severe injuries, suggested by the smaller proportion of uninsured patients who were trapped at the accident or who suffered multiple significant trauma, would be associated with less treatment and lower mortality—not higher mortality as observed. While less treatment and higher mortality may be expected if the uninsured were more likely to be almost dead on arrival, estimates below suggest that these cases have little effect on the estimates. The combination of less treatment and higher mortality suggests that the results are not due to systematic differences in injury severity.

\section{Medicaid Recipients vs. the Uninsured}

Like those who do not have auto insurance, Medicaid recipients offer another interesting contrast to the uninsured. Medicaid is health insurance publicly provided to those who meet specific criteria such as members of low-income, single-parent families and disabled Supplemental Security Income recipients. If income differences were driving the earlier results, then treatment and outcomes for the uninsured should be similar to Medicaid recipients.

The groups have some major differences, however. Table 9 shows that the uninsured are older ( 29 vs. 21 ) and less likely to be female ( $29 \%$ vs. $49 \%$ ) due to eligibility requirements that favor the inclusion of mothers and children. Accordingly, the uninsured are more likely to ride a motorcycle and crash in the middle of the night. The uninsured are more likely to wear a seatbelt, though this difference goes away when adults are compared. Also, Medicaid recipients are more likely to crash in a large population area ( $26 \%$ vs. $7 \%)$.

Given that Medicaid eligibility requires a low income or a disability, this group may have worse underlying health status than the uninsured. This can also be seen from the neighborhoods 
where Medicaid recipients live. They have lower median incomes $(\$ 25,000$ vs. $\$ 28,000)$, and have larger nonwhite populations ( $26 \%$ vs. $8 \%$ ). Despite these differences, Medicaid recipients have similar areas of injury and car sizes (engine and vehicle weights).

Table 10 shows results for treatment and mortality. The effects are magnified, suggesting that income differences between the insured and uninsured are not driving the earlier results. The uninsured receive substantially less treatment $(37 \log$ points fewer charges and $50 \log$ points fewer days in care), and have even higher mortality (by 4.7 percentage points). Retransforming the estimates to percentage terms, the uninsured are found to receive forty-eight and fifty-one percent fewer facility charges and shorter lengths of stay, respectively. At the sample mean of the control variables, this represents a $\$ 9,800$ difference in facility charges and 5.7 fewer days in care. $^{27}$

While the combination of lower treatment levels and higher mortality for the uninsured provides additional support for the earlier results, the difference in treatment is much larger. A likely explanation is that differences in the Medicaid population make comparisons difficult. Medicaid recipients are likely to have poorer underlying health status due to disability eligibility and the effects of poverty. Unlike the privately insured, they may become incapacitated more easily and require more treatment due to their chronic health problems, despite less severe injuries in the crash. This would partly explain the larger treatment and mortality differences. Accordingly, male Medicaid recipients, who are almost always eligible due to disability requirements, have substantially larger treatment differences compared to women, many of whom qualify due to income standards. Also, treatment differences are smaller comparing

\footnotetext{
${ }^{27}$ When re-transforming the estimates, the average exponentiated residuals in the charges regression are 1.41 for the uninsured and 1.87 for the insured. For length of stay, they are 1.33 and 1.65. The predicted values of the retransformed charges and length of stay for the insured are \$20,452 and 11.1 days, evaluated at the sample mean of the control variables.
} 
children in Medicaid and those who are privately insured, as they usually qualify for Medicaid due to family-income standards instead of disability.

Another explanation for the larger treatment difference is that Wisconsin Medicaid reimbursement rules may encourage greater treatment levels. In Wisconsin, many of the cases studied here qualify for 'outlier' payments—additional funds from Medicaid based on their high cost. That is, additional charges mean additional reimbursement at the margin. ${ }^{28}$ In contrast, most private insurers contract with each hospital and pay on a capitated basis - the hospital is paid a fixed amount for each individual treated as an inpatient. These results suggest that Medicaid's cost-based reimbursement scheme may lead to greater treatment levels.

Further, mandated benefits in Wisconsin's Medicaid program appear to be generous, which may prevent contractors, such as HMOs that manage part of the program, from restricting physician choices. Duggan (2000) shows that Medicaid patients were more profitable in California over this period. ${ }^{29}$ This may be true in Wisconsin as well, as Medicaid appears to be more generous there than in California. ${ }^{30}$ In addition, Skinner and Silverman (2001) and Dafny (2002), among others, show that payments can vary substantially within illness categories. They find evidence that hospitals categorize Medicare patients in diagnostic groups that offer greater payments. Consistent with this notion "upcoding" in the Medicaid program, the introduction of controls for diagnosis-related groups decreases the treatment differences as discussed below.

Finally, the larger treatment differences may be due to more adequately matched samples in terms of unobserved injury severity. If the uninsured suffered from worse injuries in ways

\footnotetext{
${ }^{28}$ When costs exceed reimbursement by $\$ 31,000$ for large hospitals and $\$ 5,100$ for small hospitals, Medicaid reimbursement is roughly fifty percent of the hospital charges above the threshold.

${ }^{29}$ This was done through additional subsidies to hospitals with large shares of low-income patients, paid on a perdiem basis for Medicaid recipients. While Wisconsin did not take as large a part in this Federal program as California did, Wisconsin did begin its own initiative to subsidize the treatment of Medicaid patients in such hospitals.
} 
that are not controlled, then the magnitude of the estimated treatment differences would be smaller than the true differences. This would imply that the results comparing the uninsured with the privately insured may understate the effect of insurance on treatment, though this would be inconsistent with the mortality differences found. ${ }^{31}$ This possibility was tested using a propensity score approach (Rosenbaum and Rubin, 1983) for the uninsured versus privately insured comparison, and similar results were found. ${ }^{32}$

\section{Robustness to Sample Changes and Additional Controls}

The results are robust across a number of specifications as shown in Table 11. For example, the results are similar for samples including: the entire data set, all ages, adults less than sixty-five years old, patients who did not use a seatbelt or safety seat, and all those who traveled by ambulance even if they were not judged by police to be incapacitated. For the ambulance transfer sample, the coefficient on being uninsured in the mortality equation is 0.01 . This is again quite large given that the mortality rate in this subset is $2.5 \%$.

\footnotetext{
${ }^{30}$ According to the Health Care Financing Administration (HCFA), Medicaid spending per recipient is nearly twice as large in Wisconsin compared to California (www.hcfa.gov).

31 Another explanation would be that the most severely-injured uninsured patients were deemed disabled and therefore eligible for Medicaid. In this case, the remaining uninsured patients would necessarily receive lower treatment levels. However, the expected payer is defined as the person or organization to which the bill was originally submitted. According to Wisconsin hospital administrators, determining Medicaid eligibility usually takes over five months-long after most patients are discharged. As shown below, the comparisons are robust to restricting the sample to stays that were less than one month.

32 The propensity score is a predicted probability that a given patient is uninsured, using all of the control variables to predict whether the patient has insurance or not. Within deciles of these scores, the control variables are similar, or balanced, and it is hoped that the unobserved characteristics are also similar. The largest treatment differences are in the decile least likely to be uninsured, with coefficients of -.31 and -.39 . For the remaining deciles, the charges coefficient varies from -.27 to -.035 , with the most likely to be insured decile recording a coefficient of .203. For length of stay, the top nine deciles have coefficients ranging from -.33 to -.11 in the most likely to be insured decile. In the next to most likely to be insured decile the difference in length of stay is -.18. For mortality, the top and bottom deciles show no mortality effect, with the least likely to be insured showing a negative coefficient. For the remaining eight deciles, the coefficients range from .006 to .067 , with most close to 0.2 . Not surprisingly, the mortality results are noisier given the smaller sample sizes, but the lack of a pattern as the likelihood of being uninsured increases suggests that severity of injury did not systematically increase with the propensity to be uninsured.
} 
Car drivers are considered separately, as a comparison to the auto insurance-health insurance comparison, with the addition of DUI and at-fault indicators. Results are not sensitive to this restriction.

Trimming the data of large and small observations does not affect the results. If uninsured patients were more likely to be very close to death when entering the hospital, then treatment may be lower for these patients. Table 10 shows that removing patients who were given little treatment from the analysis does not alter the results. Similarly, the re-transformed estimates are not affected by trimming.

To consider patient decisions, the results are robust to dropping observations where the patient left the hospital "against medical advice." This happens in rare cases, though not surprisingly more frequently for the uninsured ( $1.4 \%$ vs. $0.3 \%)$. However, Table 11 shows that the results are not sensitive to dropping these observations.

The main results use ZIP code characteristics to control for patient demographics such as race, education, and income. Another way to proceed would be to use ZIP code fixed-effects. While finding one percentage-point mortality differences within ZIP codes within hospitals would appear to ask too much of the data, Table 11 shows similar results when ZIP code fixed effects are included. ${ }^{33}$

The adequacy of controlling for injury severity is also considered. The results are similar when dummy variables for 128 diagnostic related groups (DRG) are introduced. While including the five major diagnostic categories served to control for the broad area of injury, these groups are more specific. For example, DRGs include "peripheral and cranial nerve and other nerve system procedures" and "major chest trauma without complications or comorbitites". However, the DRG is defined by diagnoses that may be related to insurance status. If the 
uninsured were given less care, they would be compared to insured patients who were less severely injured. This would tend to shrink the treatment differences and widen the mortality differences. While the coefficients move in those directions, the similar results further demonstrate the robustness of the findings.

Table 11 also reports the treatment results in models where the level of treatment is used as the dependent variable, instead of using the natural log transformation. Differences in treatment increase for total facility charges to $\$ 4,100$, and are similar for length of stay -1.6 days.

Finally, Table 11 shows that the auto insurance-health insurance comparison and the Medicaid comparison are robust as well. The Medicaid differences are larger for men, who are much more likely to have a disability to become eligible. Consistent with upcoding, the use of DRG fixed effects yields smaller treatment differences, but larger mortality differences, particularly in the Medicaid comparison.

\section{Implications}

Previous studies found that the uninsured received approximately $40 \%$ less health care than the insured, though some estimates are as low as twenty-five percent (Marquis and Long (1994) offer a review, Haas and Goldman (1994) show results for emergency care). The estimates here are at the low end of this range, suggesting that previous estimates of treatment differences may have had substantial selection bias.

While the treatment difference is less than previously found, it is still substantial and represents a relatively low cost of saving a statistical life. The difference in facility charges is

\footnotetext{
${ }^{33}$ The data are restricted to ZIP codes and Hospitals where at least one uninsured patient is present.
} 
estimated to be $\$ 3,300$ at the sample mean of the control variables. ${ }^{34}$ With an increased mortality rate of 1.5 percentage points, the implied cost of saving a statistical life, then, is roughly $\$ 220,000(=\$ 3,300 / 0.015)$. For the Medicaid-uninsured comparison, the implied cost of saving a statistical life is $\$ 209,000$.

This is much cheaper than most attempts to lower mortality, especially given how young the uninsured are. Tengs et.al. (1995) discuss five hundred life-saving interventions and find that the median cost per life-year saved from fatal injury reductions is $\$ 48,000$. For other interventions such as toxin control, the estimate increases to $\$ 2.8$ million. Given the $\$ 220,000$ cost of saving a statistical life attributed to health insurance, the comparable figure here would be approximately $\$ 11,000$ per life-year saved. ${ }^{35}$

To place the increased risk of death in context, it is larger than a more commonly considered effect of health provider actions_complications or misadventures during surgery. It is estimated that there is a thirty-percent chance of being in a serious automobile accident in a lifetime. ${ }^{36}$ Say the insured and uninsured face that same risk, but the uninsured are more likely to die by 1.5 percentage points. This implies that the uninsured have a 0.45 percentage point increase in the lifetime risk of dying due to severe automobile accidents. This is over five times the lifetime risk of dying due to complications or misadventures during surgery.

\footnotetext{
${ }^{34}$ Cost audits performed by Medicaid and Medicare suggest that the cost of the treatment is roughly seventy percent of charges, consistent with private insurers typically contracting with hospitals to pay seventy-five to eighty percent of charges. However, items that are excluded from facility charges, such as physician fees, roughly offset this adjustment. Comparing aggregate data for total charges and total facility charges in Wisconsin reveals that total facility charges are seventy-two percent of total charges. Note that these cost audits reveal that accounting procedures do vary by hospital —one reason why exploiting within-hospital variation is important.

${ }_{35}$ Assuming an equal cost per life-year saved and a discount rate of $5 \%$, the discounted present value of spending $\$ 11,000$ each year in perpetuity would be approximately $\$ 220,000$ - the cost of saving a statistical life calculated above.

${ }^{36}$ The National Safety Council calculates the lifetime risk of death in an automobile accident to be roughly $1.25 \%$. This is roughly consistent with the estimated thirty-percent chance of a severe accident and a $4 \%$ chance of death once in a severe accident. The lifetime risk of death due to complications or misadventures during surgery is calculated to be $0.08 \%$.
} 
Taking this calculation one step further, it is possible to place a rough value on having insurance. If the value were much larger than the cost of insurance, then these results may be regarded as "too big." It appears, however, that the cost of catastrophic health insurance is similar in magnitude to the value of the reduction in mortality. Taking the 0.45 percentage point decrease in lifetime risk, and assuming, for the moment, that each year is an independent and equal risk, then the annual decrease in the risk of death for an insured adult is on the order of 0.01 percentage points. Given a value of life estimate of three million dollars, the willingness to pay for a 0.01 percentage point decrease in the annual risk of death would be approximately $\$ 300(=\$ 3,000,000 * 0.0001)$ per year. In a casual survey of catastrophic insurance rates in Wisconsin, a policy with a $\$ 1500$ deductible was found to be approximately $\$ 300$ per year for a twenty-three year old man. It appears, then, that the magnitudes of the benefits and costs of catastrophic insurance are roughly similar and that the differences in treatment and mortality are not unreasonably large.

\section{Flat-of-the-curve Medicine}

There is a debate in the health literature over whether diminishing returns have set in on the ability of health care to improve outcomes. Physicians may be practicing 'flat-of-the-curve' medicine, as discussed in section two. An empirical test of the effectiveness of additional treatment is complicated by the fact that more severely ill patients receive more health care. For example, Table 2 shows that for patients who die — the most severely injured—-total facility charges are greater. More treatment is associated with worse health outcomes.

The analysis here suggests that we are not on the "flat-of-the-curve". An alternative characterization of the results is to consider insurance status as an instrumental variable for treatment. If insurance status were related to treatment levels because providers are sensitive to 
the patient's ability-to-pay, and not due to differences in unobserved injury severity, then insurance status could used as an instrumental variable for treatment. This would break the spurious positive relationship between treatment and mortality. The first stage is represented in Table 3 where treatment is regressed on insurance status to calculate the predicted facility charges. The second stage, which predicts the probability of death, reveals a coefficient on the instrumented charges of -0.110 with a standard error of 0.047 . This implies that a ten percent increase in facility charges is associated with a reduction in the mortality rate of roughly 1.1 percentage points. $^{37}$ Again, this is a large difference as suggested by the low cost per statistical life saved calculated above. It appears that when it comes to emergency medicine, we are not on the "flat of the curve".

If evidence had been found for flat-of-the-curve medicine, then welfare implications would stem from distorted insurance prices. However, with mortality differences, the welfare implications are not straightforward. The uninsured may receive too little care, the insured may receive too much, or both.

\section{Conclusion}

Using automobile accidents as unexpected health shocks where contact with medical professionals is virtually automatic, this paper avoids selection problems inherent in previous studies. The results suggest that there are real consequences to being uninsured. Controlling for personal, crash, vehicle, neighborhood, and hospital characteristics, the uninsured are estimated to receive $20 \%$ less treatment than the privately insured following serious accidents. In addition, there appear to be large effects on mortality. The uninsured are found to have a 1.5 percentage

\footnotetext{
${ }^{37}$ This result can be derived from the above tables where the coefficient on uninsured in the mortality regression is divided by the coefficient in the facility charges regression to form an IV estimate of the effect of charges on
} 
point higher mortality rate compared with a mean mortality rate of $3.8 \%$. These estimates imply that physicians are not practicing 'flat-of-the-curve' medicine, at least in these trauma cases.

Provider sensitivity toward insurance status appears to account for the difference in care, as opposed to unobserved characteristics of the uninsured. For example, similar groups, such as drivers who have health insurance but do not have automobile insurance, receive more treatment and die less. In addition, the uninsured receive fewer major operations - decisions that are likely the domain of physicians. Finally, the combination of less treatment and higher mortality is inconsistent with systematic differences in health status between the insured and uninsured. It appears, then, that having health insurance significantly affects treatment decisions and ultimately patient outcomes.

mortality. The IV estimate on log length of stay on mortality is -0.088 with a standard error of 0.032 . 


\section{Bibliography}

Ayanian, J.Z., Kohler, B.A., Abe, T. and A. M Epstein. "The Relation Between Health Insurance Coverage and Clinical Outcomes Among Women with Breast Cancer." New England Journal of Medicine. 329(5). July 29, 1993: 326-31

Brown, M. E., Bindman, A. B., and N. Lurie. "Monitoring the Consequences of Uninsurance: A Review of Methodologies." Medical Care Research and Review. 55(2). June 1998. 177-210.

CDC National Center for Health Statistics (NCHS). National Mortality Data 1997. Hyattsville (MD): NCHS 1998.

Chiappori, P.A., Jullien, B., Salanié, B and F. Salanié. "Asymmetric Information in Insurance: A Robust Characterization." Working paper, University of Chicago. 2001.

Chiappori, P.A. and B. Salanié. "Testing for Asymmetric Information on Insurance Markets." Journal of Political Economy, 108(1), 2000. 56-78.

Clyde, A. T., Hemenway, D., and J. T. Nagurney. "Seat Belt Use, Insurance Status, and Hospital Bad Debt." The Journal of Trauma. 41(1). 1996: 100-104.

Currie, Janet and Jonathan Gruber. "The Technology of Birth: Health Insurance, Medical Interventions, and Infant Health." NBER Working Paper. No. 5985. 1997.

Currie, Janet and Duncan Thomas. "Medical Care for Children: Public Insurance, Private Insurance, and Racial Differences in Utilization." Journal of Human Resources. 30(1). 1995: 135-62.

Dafny, Leemore. "How Do Hospitals Respond to Price Changes?" mimeo. Northwestern University. November 2002.

Dionne, G. and P. St-Michel. "Wokers' Compensation and Moral Hazard." The Review of Economics and Statistics. 73(2). May 1991: 236-244.

Duggan, Mark. "Hospital Ownership and Public Medical Spending." Quarterly Journal of Economics. November 2000: 1343-1373.

Enthoven, Alain C. Health Plan. Reading, MA: Addison-Wesley. 1980.

Fortin, B. and P. Lanoie. "Substitution Between Unemployment Insurance and Wokers' Compensation: An Analysis Applied to the Risk of Workplace Accidents." Journal of Public Economics. 49(3). December 1992: 287-312.

Haas, J. S. and L. Goldman. "Acutely Injured Patients with Trauma in Massachusetts: Differences in Care and Mortality, by Insurance Status." American Journal of Public Health. 84(10). October 1994: 1605-1608.

Hadley, J. Steinberg, E.P., and J. Feder. "Comparison of Uninsured and Privately Insured Hospital Patients. Condition on Admission, Resource Use, and Outcome." Journal of the American Medical Association. 265(3). January 16, 1991: 374-9.

Heckman, J., Lalonde, R., and Smith, J. "The Economics and Econometrics of Active Labor Market Programs," Handbook of Labor Economics, Volume 3, Ashenfelter, O. and D. Card, eds., Amsterdam: Elsevier Science. 1999.

Jullien, B., Salanie, B., and F. Salanie. "Should More Risk-Averse Agents Exert More Effort?" The Geneva Papers on Risk and Insurance Theory. 24. 1999: 19-28.

Kaiser Family Foundation. State Facts: Health Needs and Medicaid Financing. http://www.kff.org/docs/state/states/wi.html. February 1998.

Levy, Helen and Meltzer, David. "What Do We Really Know About Whether Health Insurance Affects Health?” JCPR Working Paper. No. 275 December 2001. 
Long, S.H., M.S. Marquis, and J. Rodgers. "Do people Shift Their Use of Health Services over Time to Take Advantage of Insurance?" Journal of Health Economics. 17. 1997: 105115.

Manning, W.G. "The Logged Dependent Variable, Heteroscedasticity, and the Retransformation Problem." Journal of Health Economics. 17(3). June 1998: 283-295.

Marquis M. S. and S. H. Long. "The Uninsured Access Gap: Narrowing the Estimates." Inquiry. 31 (4). Winter 1994/1995: 405-414.

Maza, D. de, and D.C. Webb. "Advantageous Selection in Insurance Markets". RAND Journal of Economics 32 (2). Summer 2001: 249-262.

McGuire, T.G. and R. P. Ellis. "Provider Behavior Under Prospective Reimbursement." Journal of Health Economics. 5. 1986: 129-151

National Center for Health Statistics. Health, United States, 2002 With Chartbook on Trends in the Health of Americans. Hyattsville, Maryland: 2002.

National Center for Statistics and Analysis, National Highway Traffic Safety Administration. Revised Catalog of Types of Applications Implemented Using Linked State Data. DOT HS 808 793. Washington, DC: Department of Transportation, October, 1998.

National Safety Council and ANSI. Manual on Classification of Motor Vehicle Accidents: Sixth Edition. ANSI D16.1. Itasca, IL: NSC. 1996.

Newhouse, Joseph P. Free for all? Lessons from the RAND Health Insurance Experiment. Cambridge and London: Harvard University Press. 1993.

Norton, E.C. and Staiger, D.O. "How hospital ownership affects access to care for the uninsured." The Rand Journal of Economics. 25(1) Spring1994: 171-85.

Rosenbaum, P. and D.B. Rubin. "The Central Role of the Propensity Score in Observational Studies for Causal Effects." Biometrika. 70. 1983: 41-55.

Rothschild, M. and J. E. Stiglitz, "Equilibrium in Competitive Insurance Markets: An Essay on the Economics of Imperfect Information." Quarterly Journal of Economics. 90(4) 1976: 630-49

Sada, M.J., French, W. J., Carlisle, D. M., Chandra, N. C., Gore, J. M., and W. J. Rogers. "Influence of Payor on Use of Invasive Cardiac Procedures and Patient Outcome after Myocardial Infarction in the United States." Journal of the American College of Cardiology. 31(7). June 1998: 1474-80.

Saywell, Jr. R. M., Zollinger, T. W., Chu, D. K. W., Macbeth, C. A., and M. E. Sechrist. "Hospital and Patient Characteristics of Uncompensated Hospital Care: Policy Implications." Journal of Health Politics, Policy and Law. 14(2). Summer 1989: 287307.

Sloan, 1999 "Does Where You Are Admitted Make A Difference? An Analysis of Medicare Data". NBER Working Paper. No. 6896. 1999.

Silverman, E. and J. Skinner. "Are For-Profit hospitals Really Different? Medicare Upcoding and Market Structure.” NBER Working Paper. No. 8133. 2001.

Spillman. "The Impact of Being Uninsured on Utilization of Basic Health Care Services." Inquiry. 29. 1992: 457-466.

Tengs, T.O., Adams, M.E., Pilskin, J.S., Gelb Safran, D., Siegel, J.E., Weinstein, M.C., and J.D. Graham. "Five-Hundred Life-Saving Interventions and Their Cost-Effectiveness." Risk Analysis. 15(3). 1995: 369-390. 
Tilford, J.M., Robbins, J.M., Shema, S.J., and F.L. Farmer. "Response to Health Insurance by Previously Uninsured Rural Children.” Health Services Research 34(3). 1999: 761-775. 


\section{Data Sources}

Annual Survey of Hospitals. Bureau of Health Information, Division of Health Care

Financing, Department of Health and Family Services. State of Wisconsin. 1992.

Crash Outcome Data Evaluation System. Bureau of Health Information, Division of Health Care Financing, Department of Health and Family Services. State of Wisconsin. 1992-1997.

Primedia Price Digests, a Unit of Primedia Business.

U.S. Census Bureau; 1990 Census of Population and Housing, Summary Tape File 3B: ZIP Codes.

Wisconsin Hospital Fiscal Survey. Bureau of Health Information, Division of Health Care Financing, Department of Health and Family Services. State of Wisconsin. 1992. 


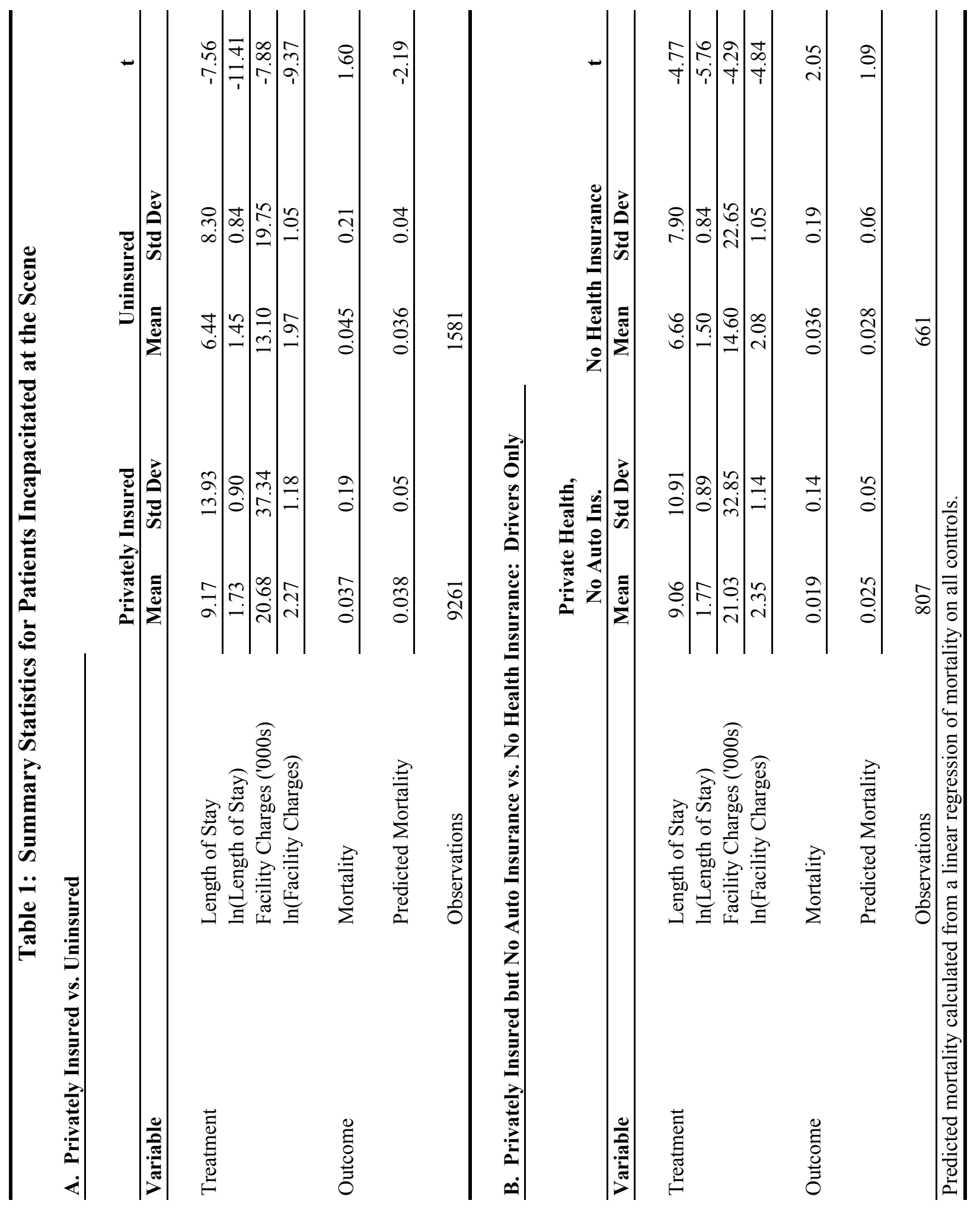




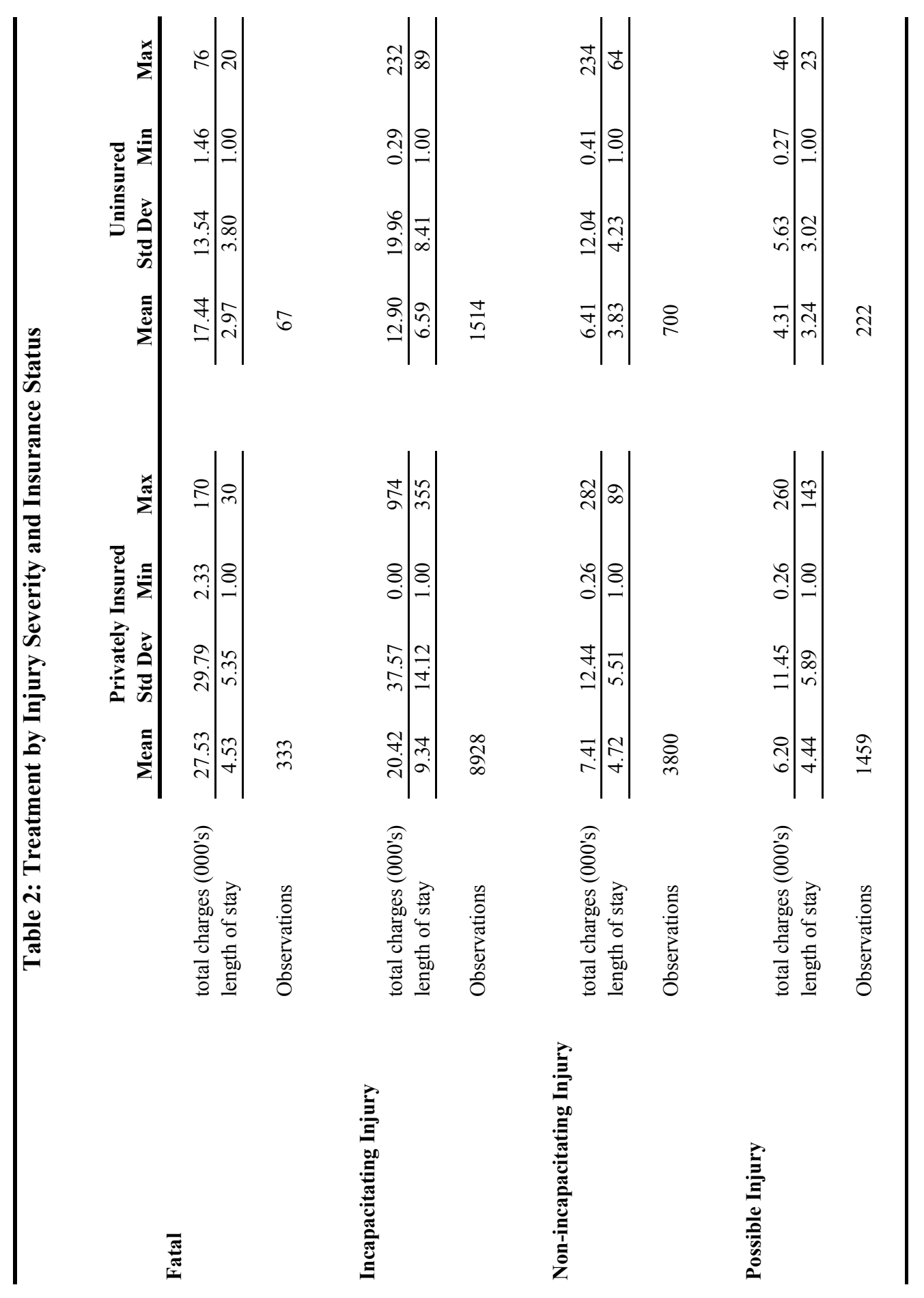


Table 3: Summary Statistics for those Incapacitated at the Scene

\begin{tabular}{|c|c|c|c|c|c|c|}
\hline \multirow{2}{*}{ Variable } & & \multicolumn{2}{|c|}{ Privately Insured } & \multicolumn{2}{|c|}{ Uninsured } & \multirow[t]{2}{*}{$\mathbf{t}$} \\
\hline & & Mean & Std Dev & Mean & Std Dev & \\
\hline \multirow{2}{*}{$\begin{array}{l}\text { Personal } \\
\text { Characteristics }\end{array}$} & age & 30 & 14 & 29 & 12 & 3.46 \\
\hline & female & 0.38 & 0.49 & 0.28 & 0.45 & 7.24 \\
\hline \multirow{4}{*}{ Vehicle Types } & car & 0.61 & 0.49 & 0.60 & 0.49 & 0.53 \\
\hline & truck & 0.14 & 0.34 & 0.13 & 0.34 & 0.38 \\
\hline & motorcycle & 0.14 & 0.35 & 0.15 & 0.36 & 1.20 \\
\hline & other vehicle & 0.12 & 0.32 & 0.12 & 0.32 & 0.09 \\
\hline \multirow{9}{*}{$\begin{array}{l}\text { Crash } \\
\text { Characteristics }\end{array}$} & car passenger & 0.23 & 0.42 & 0.25 & 0.43 & 1.77 \\
\hline & restraint seat belt/child seat & 0.30 & 0.46 & 0.19 & 0.39 & 9.59 \\
\hline & severe vehicle damage & 0.49 & 0.50 & 0.48 & 0.50 & 0.98 \\
\hline & trapped & 0.17 & 0.38 & 0.15 & 0.36 & 2.34 \\
\hline & head-on collision & 0.13 & 0.33 & 0.12 & 0.32 & 1.12 \\
\hline & angle collision & 0.29 & 0.45 & 0.22 & 0.42 & 5.76 \\
\hline & sideswipe collision & 0.04 & 0.20 & 0.05 & 0.21 & 0.75 \\
\hline & other collision & 0.54 & 0.50 & 0.61 & 0.49 & 5.64 \\
\hline & wet pavement & 0.24 & 0.43 & 0.21 & 0.41 & 2.79 \\
\hline \multirow[t]{6}{*}{ Road Types } & urban street & 0.20 & 0.40 & 0.22 & 0.42 & 2.12 \\
\hline & rural street & 0.36 & 0.48 & 0.39 & 0.49 & 1.75 \\
\hline & urban highway & 0.09 & 0.29 & 0.08 & 0.28 & 1.18 \\
\hline & rural highway & 0.30 & 0.46 & 0.27 & 0.44 & 2.36 \\
\hline & urban interstate & 0.01 & 0.12 & 0.01 & 0.09 & 2.08 \\
\hline & rural interstate & 0.03 & 0.18 & 0.03 & 0.17 & 0.29 \\
\hline \multirow[t]{4}{*}{ Day and Hour } & weekend & 0.53 & 0.50 & 0.56 & 0.50 & 2.53 \\
\hline & between $7 \mathrm{am}$ and $4 \mathrm{pm}$ & 0.37 & 0.48 & 0.30 & 0.46 & 5.28 \\
\hline & between $4 \mathrm{pm}$ and $11 \mathrm{pm}$ & 0.39 & 0.49 & 0.38 & 0.48 & 0.64 \\
\hline & between $11 \mathrm{pm}$ and $7 \mathrm{am}$ & 0.24 & 0.43 & 0.32 & 0.47 & 6.56 \\
\hline \multirow[t]{3}{*}{ Population Size } & small town $<25,000$ & 0.79 & 0.41 & 0.76 & 0.42 & 1.85 \\
\hline & medium town $<250,000$ & 0.15 & 0.36 & 0.16 & 0.36 & 0.77 \\
\hline & large town $>250,000$ & 0.07 & 0.25 & 0.08 & 0.27 & 1.95 \\
\hline \multirow{6}{*}{$\begin{array}{l}\text { Major Diagnostic } \\
\text { Categories }\end{array}$} & nervous system & 0.20 & 0.40 & 0.22 & 0.41 & 0.98 \\
\hline & respiratory & 0.07 & 0.25 & 0.07 & 0.25 & 0.21 \\
\hline & musculoskeletal \& tissue & 0.35 & 0.48 & 0.35 & 0.48 & 0.03 \\
\hline & skin, tissue, \& breast & 0.06 & 0.24 & 0.08 & 0.27 & 2.25 \\
\hline & multiple significant trauma & 0.20 & 0.40 & 0.16 & 0.37 & 3.16 \\
\hline & other & 0.11 & 0.32 & 0.12 & 0.33 & 1.13 \\
\hline \multirow[t]{2}{*}{ Fewer Observations } & airbag deployed & 2.59 & 0.86 & 2.64 & 0.83 & 1.79 \\
\hline & Observations & 9261 & & 1581 & & \\
\hline
\end{tabular}




\section{Table 3: Summary Statistics for those Incapacitated at the Scene (Cont'd)}

\begin{tabular}{|c|c|c|c|c|c|c|}
\hline \multirow{2}{*}{ Variable } & & \multicolumn{2}{|c|}{ Privately Insured } & \multicolumn{2}{|c|}{ Uninsured } & \multirow[t]{2}{*}{$\mathbf{t}$} \\
\hline & & Mean & Std Dev & Mean & Std Dev & \\
\hline \multirow{10}{*}{$\begin{array}{l}\text { Neighborhood } \\
\text { Characteristics }\end{array}$} & white & 0.94 & 0.13 & 0.92 & 0.17 & 3.52 \\
\hline & black & 0.03 & 0.11 & 0.05 & 0.15 & 2.76 \\
\hline & other race & 0.02 & 0.04 & 0.03 & 0.06 & 2.65 \\
\hline & high school dropout & 0.22 & 0.08 & 0.24 & 0.09 & 6.35 \\
\hline & high school degree & 0.38 & 0.07 & 0.38 & 0.07 & 0.08 \\
\hline & some college & 0.24 & 0.05 & 0.23 & 0.05 & 5.41 \\
\hline & college & 0.17 & 0.10 & 0.15 & 0.09 & 4.60 \\
\hline & median household income & 30726 & 8188 & 27955 & 7752 & 8.76 \\
\hline & poverty & 0.10 & 0.07 & 0.12 & 0.09 & 6.84 \\
\hline & Observations & 9040 & & 1545 & & \\
\hline \multirow{21}{*}{$\begin{array}{l}\text { Automobile } \\
\text { Characteristics }\end{array}$} & 2-door & 0.61 & 0.49 & 0.63 & 0.48 & 1.25 \\
\hline & Engine Size: $<2$ liters & 0.19 & 0.39 & 0.22 & 0.41 & 2.02 \\
\hline & $>=2 \&<2.4$ liters & 0.22 & 0.42 & 0.23 & 0.42 & 0.55 \\
\hline & $>=2.4 \&<2.9$ liters & 0.19 & 0.40 & 0.23 & 0.42 & 2.38 \\
\hline & $>2.9 \&<3.9$ liters & 0.19 & 0.39 & 0.14 & 0.35 & 3.37 \\
\hline & $>3.9$ liters & 0.20 & 0.40 & 0.18 & 0.38 & 1.68 \\
\hline & Vehicle Weight: $<2420$ pounds & 0.25 & 0.43 & 0.30 & 0.46 & 3.06 \\
\hline & $>=2420 \&<2830$ pounds & 0.24 & 0.43 & 0.26 & 0.44 & 0.83 \\
\hline & $>=2830 \&<3730$ pounds & 0.26 & 0.44 & 0.22 & 0.41 & 2.73 \\
\hline & $>=3730$ pounds & 0.25 & 0.43 & 0.23 & 0.42 & 1.15 \\
\hline & MSRP: $<=\$ 7435$ & 0.15 & 0.36 & 0.22 & 0.42 & 5.58 \\
\hline & $>\$ 7435 \&<=\$ 9027$ & 0.16 & 0.37 & 0.19 & 0.39 & 2.06 \\
\hline & $>\$ 9035 \&<=\$ 10400$ & 0.16 & 0.37 & 0.18 & 0.38 & 1.62 \\
\hline & $>\$ 10400 \&<=\$ 12320$ & 0.17 & 0.37 & 0.16 & 0.37 & 0.48 \\
\hline & $>\$ 12320 \&<=\$ 15470$ & 0.18 & 0.39 & 0.15 & 0.35 & 2.85 \\
\hline & $>\$ 15470$ & 0.18 & 0.39 & 0.11 & 0.31 & 5.64 \\
\hline & Vehicle Age: $<=4$ years-old & 0.28 & 0.45 & 0.19 & 0.39 & 5.71 \\
\hline & $>4 \&<=7$ years-old & 0.26 & 0.44 & 0.20 & 0.40 & 3.61 \\
\hline & $>7 \&<=10$ years-old & 0.27 & 0.44 & 0.29 & 0.45 & 1.36 \\
\hline & $>10$ years-old & 0.20 & 0.40 & 0.32 & 0.47 & 8.47 \\
\hline & Observations & 5767 & & 901 & & \\
\hline
\end{tabular}

Vehicle Weight data has 5,340 observations for the privately insured and 773 for the uninsured.

Neighborhood characteristics are population fractions at the ZIP code level and t-tests use standard errors clusterd by ZIP. 


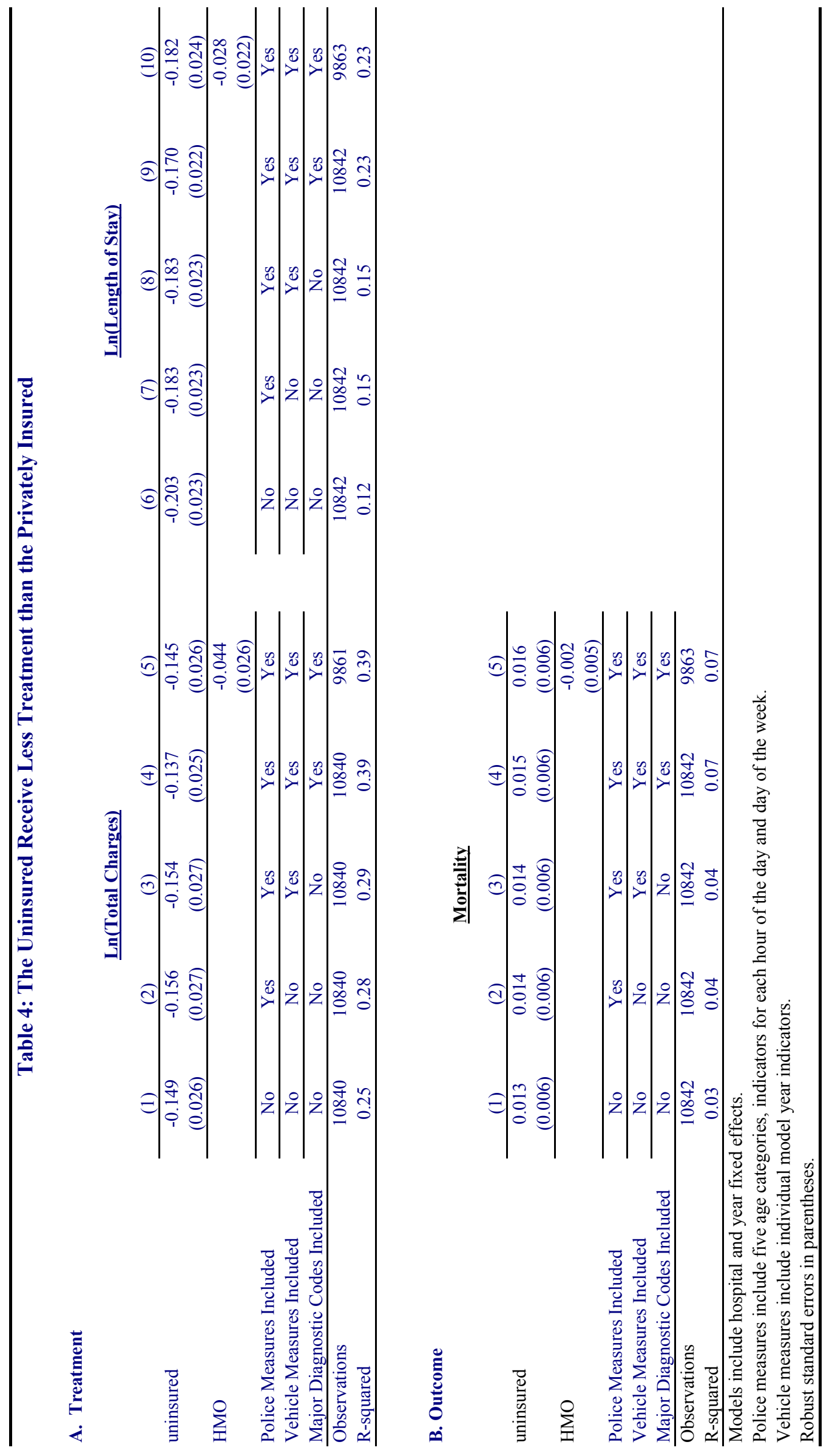


Table 5: Hospital Comparisons

\begin{tabular}{|c|c|c|c|c|c|}
\hline & & Uninsured Coeff. & Std Error & $\begin{array}{l}\text { Mean of } \\
\text { Dep. Var }\end{array}$ & Obs. \\
\hline \multirow[t]{3}{*}{ Main Results } & Ln (Charges) & -0.137 & $(0.025)$ & 2.225 & 10840 \\
\hline & Ln (Length of Stay) & -0.170 & $(0.022)$ & 1.692 & 10842 \\
\hline & Mortality & 0.015 & $(0.006)$ & 0.038 & 10842 \\
\hline
\end{tabular}

Hospitals with greater than median:

\begin{tabular}{|c|c|c|c|c|c|c|}
\hline \multirow[t]{4}{*}{ Generosity } & Charity Care & $\begin{array}{l}\text { Ln (Charges) } \\
\text { Ln (Length of Stay) } \\
\text { Mortality }\end{array}$ & $\begin{array}{c}-0.149 \\
-0.180 \\
0.016 \\
\end{array}$ & $\begin{array}{l}(0.032) \\
(0.029) \\
(0.008) \\
\end{array}$ & $\begin{array}{l}2.361 \\
1.781 \\
0.042 \\
\end{array}$ & $\begin{array}{l}6961 \\
6961 \\
6961 \\
\end{array}$ \\
\hline & \multirow[t]{3}{*}{ Bad Debt } & Ln (Charges) & -0.141 & $(0.037)$ & 2.242 & 4137 \\
\hline & & Ln (Length of Stay) & -0.175 & $(0.034)$ & 1.648 & 4137 \\
\hline & & Mortality & 0.015 & $(0.008)$ & 0.036 & 4137 \\
\hline \multirow[t]{9}{*}{ Resources } & \multirow[t]{3}{*}{ Return on Assets } & Ln (Charges) & -0.169 & $(0.032)$ & 2.298 & 6912 \\
\hline & & Ln (Length of Stay) & -0.206 & $(0.029)$ & 1.749 & 6912 \\
\hline & & Mortality & 0.016 & $(0.008)$ & 0.044 & 6912 \\
\hline & \multirow[t]{3}{*}{ Intensive Care Unit Beds } & Ln (Charges) & -0.187 & $(0.034)$ & 2.379 & 6655 \\
\hline & & Ln (Length of Stay) & -0.205 & $(0.031)$ & 1.784 & 6657 \\
\hline & & Mortality & 0.010 & $(0.008)$ & 0.045 & 6657 \\
\hline & \multirow[t]{3}{*}{ Revenue from Public Sources } & Ln (Charges) & -0.120 & $(0.033)$ & 2.392 & 6690 \\
\hline & & Ln (Length of Stay) & -0.178 & $(0.030)$ & 1.774 & 6692 \\
\hline & & Mortality & 0.022 & $(0.008)$ & 0.045 & 6692 \\
\hline \multicolumn{7}{|c|}{ Hospitals categorized as: } \\
\hline & \multirow[t]{3}{*}{ Teaching } & Ln (Charges) & -0.340 & $(0.069)$ & 2.835 & 2435 \\
\hline & & Ln (Length of Stay) & -0.423 & $(0.064)$ & 1.979 & 2435 \\
\hline & & Mortality & 0.056 & $(0.020)$ & 0.070 & 2435 \\
\hline & \multirow[t]{3}{*}{ Non-Teaching } & Ln (Charges) & -0.085 & $(0.026)$ & 2.048 & 8405 \\
\hline & & Ln (Length of Stay) & -0.110 & $(0.023)$ & 1.609 & 8407 \\
\hline & & Mortality & 0.007 & $(0.006)$ & 0.028 & 8407 \\
\hline \multirow[t]{6}{*}{ Mission } & \multirow[t]{3}{*}{ Religiously-Affiliated } & Ln (Charges) & -0.100 & $(0.045)$ & 2.050 & 3248 \\
\hline & & Ln (Length of Stay) & -0.119 & $(0.041)$ & 1.666 & 3248 \\
\hline & & Mortality & -0.008 & $(0.008)$ & 0.031 & 3248 \\
\hline & \multirow[t]{3}{*}{ Non-Religiously Affiliated } & Ln (Charges) & -0.122 & $(0.031)$ & 2.155 & 5758 \\
\hline & & Ln (Length of Stay) & -0.161 & $(0.028)$ & 1.611 & 5760 \\
\hline & & Mortality & 0.024 & $(0.008)$ & 0.041 & 5760 \\
\hline
\end{tabular}

Models include hospital and year fixed effects;

Police measures include five age categories, indicators for each hour of the day and day of the week;

Vehicle measures include individual model year indicators.

Robust standard errors in parentheses. 


\begin{tabular}{|c|c|c|c|c|c|c|}
\hline \multirow[b]{2}{*}{ Variable } & le 6: Summary Statist & \multicolumn{2}{|c|}{$\begin{array}{l}\text { Privately Insured } \\
\text { w/ No Auto Ins. }\end{array}$} & \multicolumn{2}{|c|}{ No Health Insurance } & \multirow[t]{2}{*}{$\mathbf{t}$} \\
\hline & & Mean & Std Dev & Mean & Std Dev & \\
\hline Personal & age & 30 & 11 & 31 & 11 & 0.67 \\
\hline Characteristics & female & 0.24 & 0.43 & 0.27 & 0.44 & 1.28 \\
\hline \multirow[t]{3}{*}{ Vehicle Types } & car & 0.49 & 0.50 & 0.63 & 0.48 & 5.22 \\
\hline & truck & 0.09 & 0.29 & 0.13 & 0.34 & 2.59 \\
\hline & motorcycle & 0.42 & 0.49 & 0.24 & 0.43 & 7.29 \\
\hline \multirow{8}{*}{$\begin{array}{l}\text { Crash } \\
\text { Characteristics }\end{array}$} & restraint (seat belt) & 0.14 & 0.35 & 0.23 & 0.42 & 4.62 \\
\hline & severe vehicle damage & 0.43 & 0.49 & 0.53 & 0.50 & 4.07 \\
\hline & trapped & 0.13 & 0.33 & 0.18 & 0.39 & 3.11 \\
\hline & head-on collision & 0.11 & 0.31 & 0.16 & 0.37 & 2.78 \\
\hline & angle collision & 0.26 & 0.44 & 0.23 & 0.42 & 1.41 \\
\hline & sideswipe collision & 0.05 & 0.21 & 0.06 & 0.24 & 1.42 \\
\hline & other collision & 0.59 & 0.49 & 0.55 & 0.50 & 1.33 \\
\hline & wet pavement & 0.17 & 0.37 & 0.21 & 0.41 & 2.38 \\
\hline \multirow[t]{6}{*}{ Road Types } & urban street & 0.23 & 0.42 & 0.17 & 0.38 & 2.80 \\
\hline & rural street & 0.38 & 0.49 & 0.41 & 0.49 & 1.26 \\
\hline & urban highway & 0.11 & 0.31 & 0.10 & 0.29 & 0.78 \\
\hline & rural highway & 0.25 & 0.43 & 0.29 & 0.45 & 1.73 \\
\hline & urban interstate & 0.01 & 0.12 & 0.01 & 0.08 & 1.46 \\
\hline & rural interstate & 0.02 & 0.14 & 0.03 & 0.16 & 0.89 \\
\hline \multirow[t]{4}{*}{ Day and Hour } & weekend & 0.60 & 0.49 & 0.57 & 0.50 & 1.09 \\
\hline & between $7 \mathrm{am}$ and $4 \mathrm{pm}$ & 0.29 & 0.46 & 0.32 & 0.47 & 1.04 \\
\hline & between $4 \mathrm{pm}$ and $11 \mathrm{pm}$ & 0.40 & 0.49 & 0.37 & 0.48 & 1.11 \\
\hline & between $11 \mathrm{pm}$ and $7 \mathrm{am}$ & 0.31 & 0.46 & 0.31 & 0.46 & 0.13 \\
\hline \multirow[t]{3}{*}{ Population Size } & small town $<25,000$ & 0.73 & 0.44 & 0.81 & 0.39 & 3.76 \\
\hline & medium town $<250,000$ & 0.18 & 0.38 & 0.14 & 0.34 & 2.24 \\
\hline & large town $>250,000$ & 0.09 & 0.29 & 0.05 & 0.22 & 2.95 \\
\hline \multirow{6}{*}{$\begin{array}{l}\text { Major Diagnostic } \\
\text { Categories }\end{array}$} & nervous system & 0.19 & 0.39 & 0.18 & 0.39 & 0.37 \\
\hline & respiratory & 0.05 & 0.23 & 0.06 & 0.25 & 0.78 \\
\hline & musculoskeletal \& tissue & 0.39 & 0.49 & 0.38 & 0.49 & 0.13 \\
\hline & skin, tissue, \& breast & 0.06 & 0.23 & 0.08 & 0.27 & 1.37 \\
\hline & multiple significant trauma & 0.17 & 0.38 & 0.16 & 0.37 & 0.66 \\
\hline & other & 0.14 & 0.34 & 0.13 & 0.34 & 0.21 \\
\hline \multirow[t]{2}{*}{ Driver Indicators } & at fault & 0.71 & 0.45 & 0.77 & 0.42 & 2.36 \\
\hline & DUI alcohol & 0.38 & 0.49 & 0.42 & 0.49 & 1.24 \\
\hline \multirow[t]{2}{*}{ Available 1994-1997 } & airbag deployed & 2.78 & 0.70 & 2.71 & 0.71 & 1.59 \\
\hline & Observations & 807 & & 671 & & \\
\hline
\end{tabular}

Data are for drivers only;

Airbag Deployment has 462 observations for no auto insurance and 447 observations for no health insurance. 


\section{Table 6: Summary Statistics: No Auto Insurance vs. No Health Insurance (Cont'd)}

Privately Insured

w/ No Auto Ins.

\begin{tabular}{|c|c|c|c|c|c|c|}
\hline \multirow{2}{*}{\multicolumn{2}{|c|}{ Variable }} & \multicolumn{2}{|c|}{ W/ NO AUTO MIs. } & \multicolumn{2}{|c|}{ No neaitin insur ance } & \multirow[t]{2}{*}{ t } \\
\hline & & Mean & Std Dev & Mean & Std Dev & \\
\hline \multirow{10}{*}{$\begin{array}{l}\text { Neighborhood } \\
\text { Characteristics }\end{array}$} & white & 0.93 & 0.14 & 0.93 & 0.14 & 0.03 \\
\hline & black & 0.04 & 0.12 & 0.04 & 0.13 & 0.51 \\
\hline & other race & 0.03 & 0.06 & 0.03 & 0.04 & 1.02 \\
\hline & high school dropout & 0.23 & 0.08 & 0.23 & 0.08 & 1.10 \\
\hline & high school degree & 0.39 & 0.07 & 0.38 & 0.07 & 0.59 \\
\hline & some college & 0.23 & 0.04 & 0.23 & 0.05 & 1.40 \\
\hline & college & 0.15 & 0.09 & 0.15 & 0.09 & 0.18 \\
\hline & median household income & 29432 & 7162 & 28890 & 7657 & 1.27 \\
\hline & poverty & 0.10 & 0.08 & 0.11 & 0.08 & 1.33 \\
\hline & Observations & 790 & & 657 & & \\
\hline \multirow{21}{*}{$\begin{array}{l}\text { Automobile } \\
\text { Characteristics }\end{array}$} & 2-door & 0.65 & 0.48 & 0.61 & 0.49 & 1.08 \\
\hline & Engine Size: $<2$ liters & 0.25 & 0.43 & 0.23 & 0.42 & 0.59 \\
\hline & $>=2 \&<2.4$ liters & 0.22 & 0.41 & 0.26 & 0.44 & 1.30 \\
\hline & $>=2.4 \&<2.9$ liters & 0.21 & 0.41 & 0.24 & 0.43 & 1.13 \\
\hline & $>2.9 \&<3.9$ liters & 0.13 & 0.34 & 0.12 & 0.32 & 0.58 \\
\hline & $>3.9$ liters & 0.19 & 0.40 & 0.15 & 0.36 & 1.55 \\
\hline & Vehicle Weight: $<2420$ pounds & 0.33 & 0.47 & 0.31 & 0.46 & 0.48 \\
\hline & $>=2420 \&<2830$ pounds & 0.23 & 0.42 & 0.28 & 0.45 & 1.50 \\
\hline & $>=2830 \&<3730$ pounds & 0.23 & 0.42 & 0.22 & 0.42 & 0.23 \\
\hline & $>=3730$ pounds & 0.21 & 0.41 & 0.18 & 0.39 & 0.85 \\
\hline & MSRP: $<=\$ 7435$ & 0.29 & 0.45 & 0.23 & 0.42 & 1.84 \\
\hline & $>\$ 7435 \&<=\$ 9027$ & 0.21 & 0.41 & 0.21 & 0.41 & 0.10 \\
\hline & $>\$ 9035 \&<=\$ 10400$ & 0.14 & 0.35 & 0.19 & 0.39 & 1.71 \\
\hline & $>\$ 10400 \&<=\$ 12320$ & 0.14 & 0.34 & 0.14 & 0.35 & 0.11 \\
\hline & $>\$ 12320 \&<=\$ 15470$ & 0.14 & 0.35 & 0.14 & 0.35 & 0.12 \\
\hline & $>\$ 15470$ & 0.08 & 0.27 & 0.10 & 0.30 & 0.75 \\
\hline & Vehicle Age: $<=4$ years-old & 0.09 & 0.29 & 0.19 & 0.39 & 3.67 \\
\hline & $>4 \&<=7$ years-old & 0.22 & 0.41 & 0.20 & 0.40 & 0.63 \\
\hline & $>7 \&<=10$ years-old & 0.29 & 0.45 & 0.28 & 0.45 & 0.35 \\
\hline & $>10$ years-old & 0.40 & 0.49 & 0.34 & 0.47 & 1.78 \\
\hline & Observations & 347 & & 405 & & \\
\hline
\end{tabular}

Vehicle Weight data has 283 observations for the privately insured and 347 for the uninsured.

Neighborhood characteristics are population fractions at the ZIP code level and t-tests use standard errors clusterd by ZIP. 


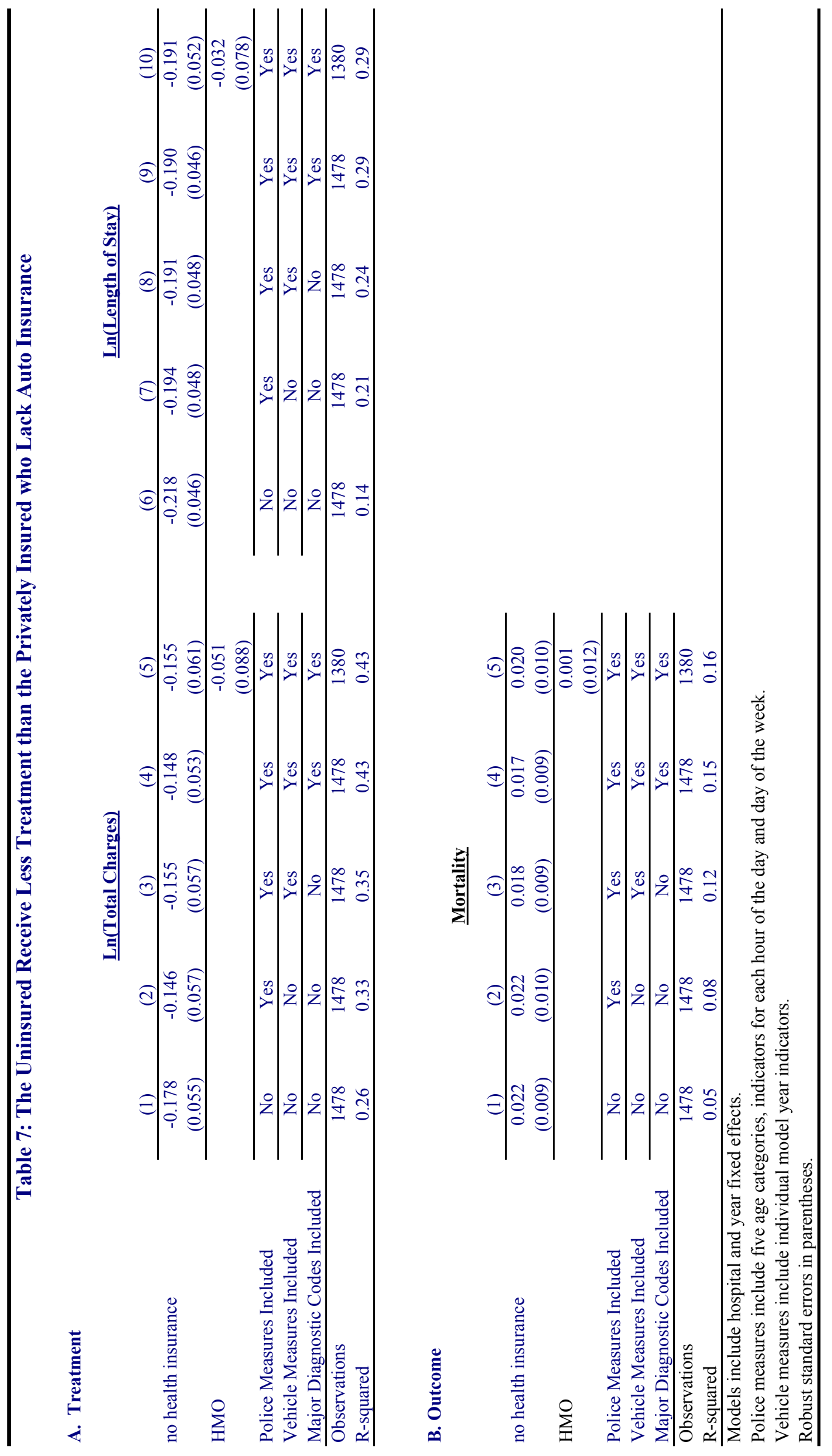




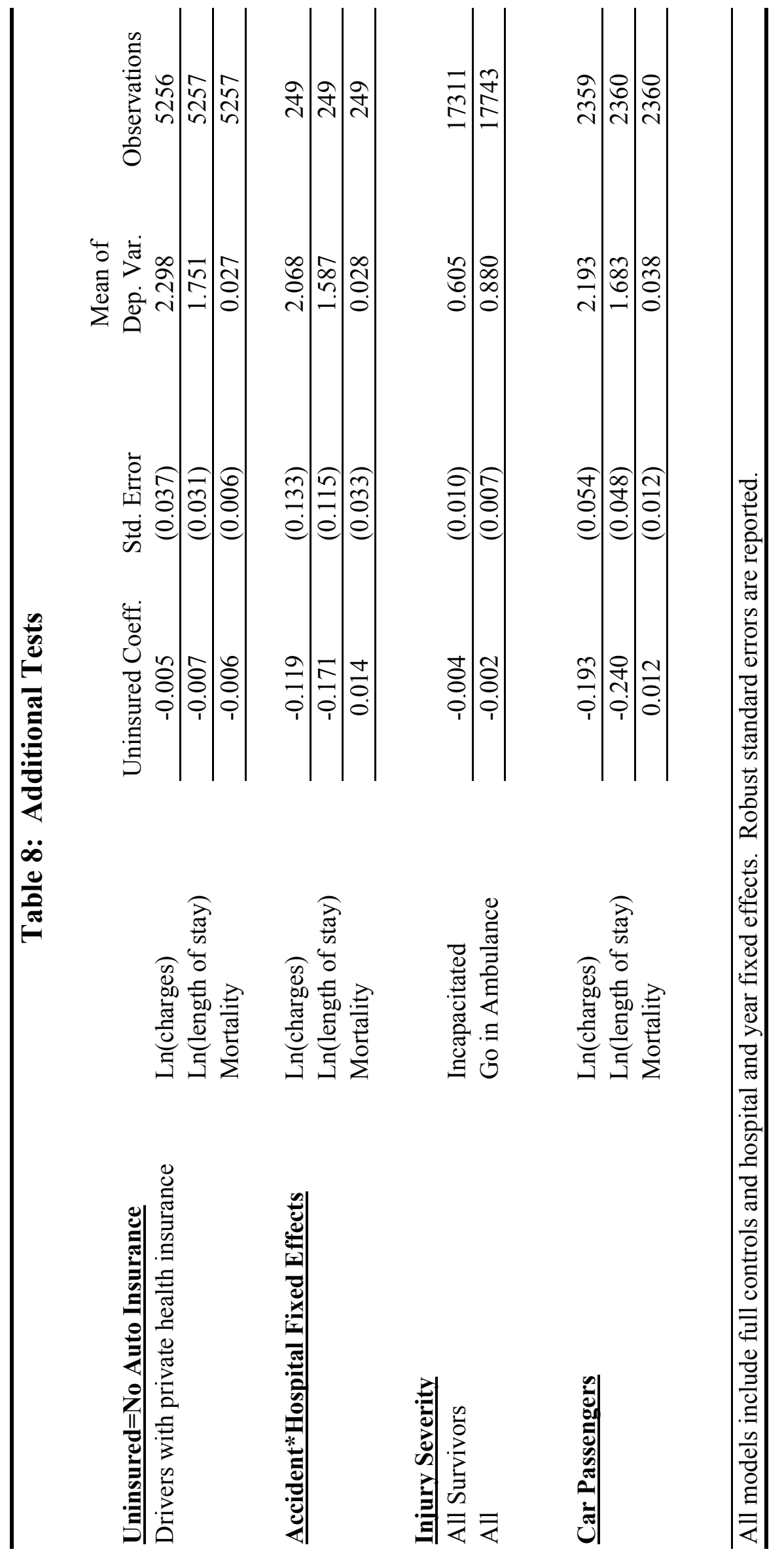




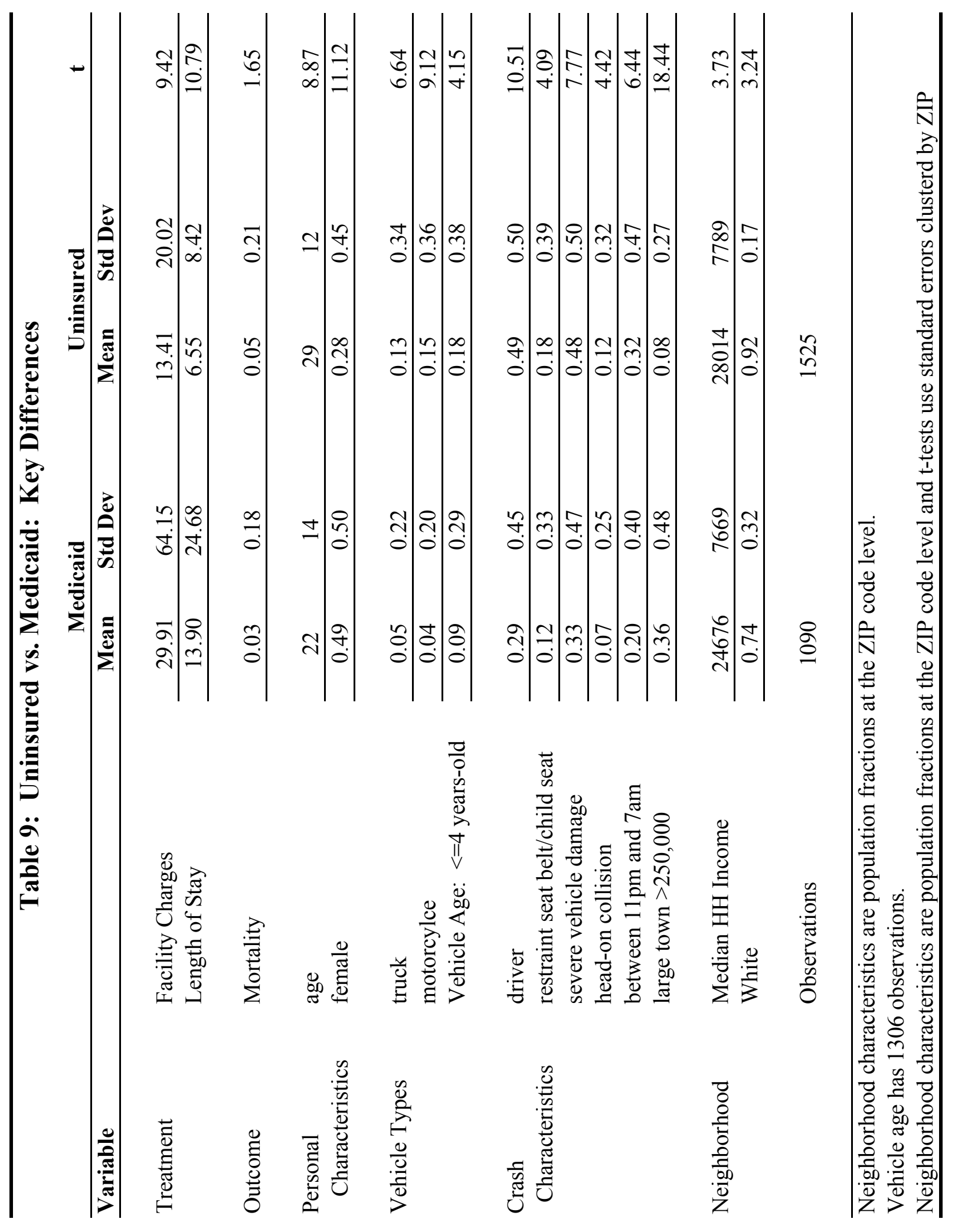




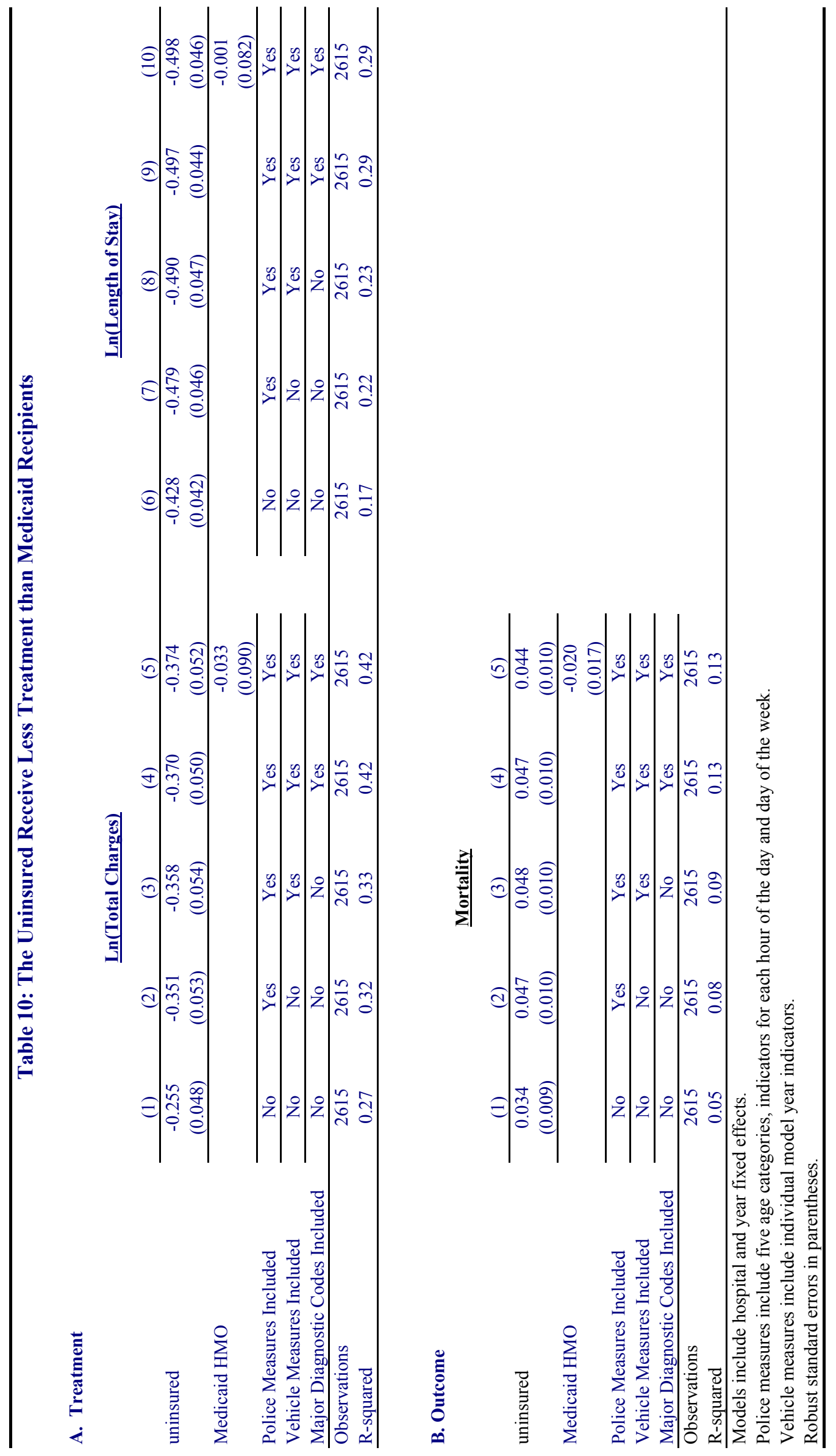




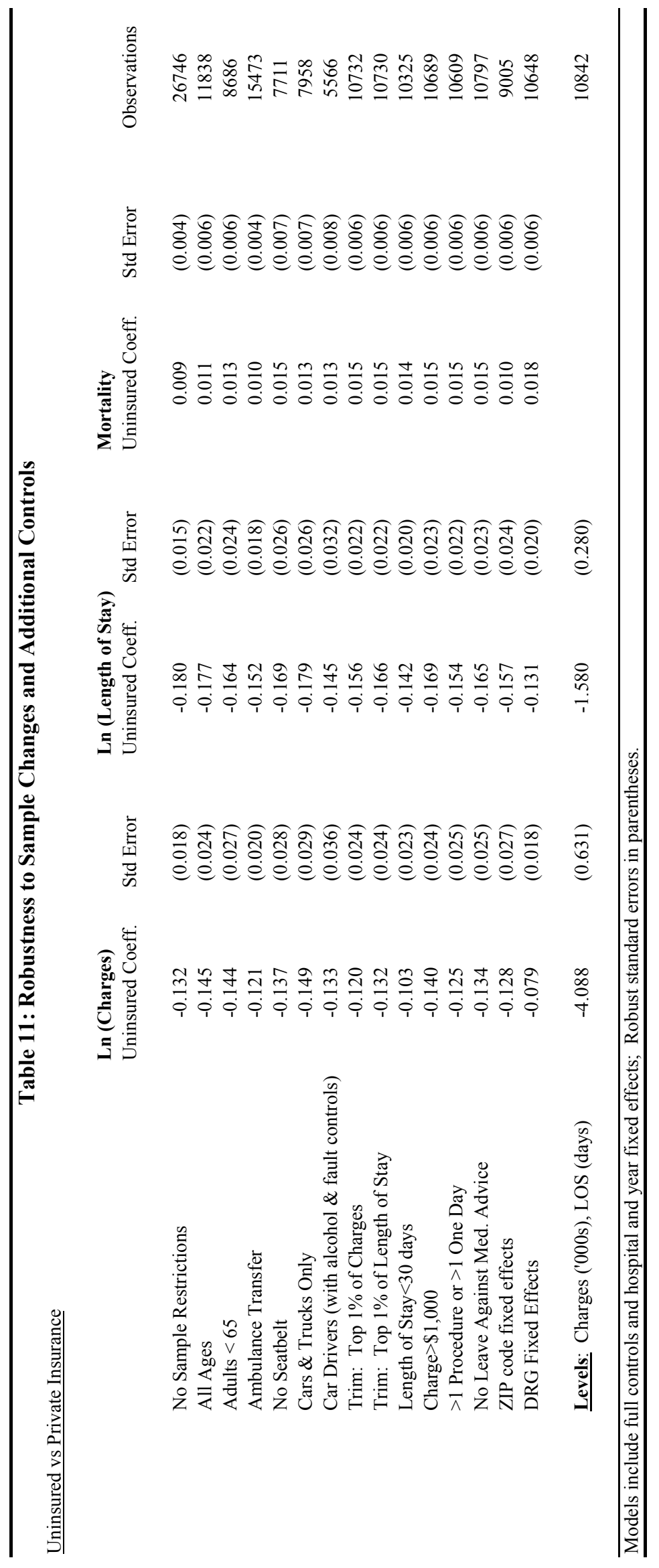




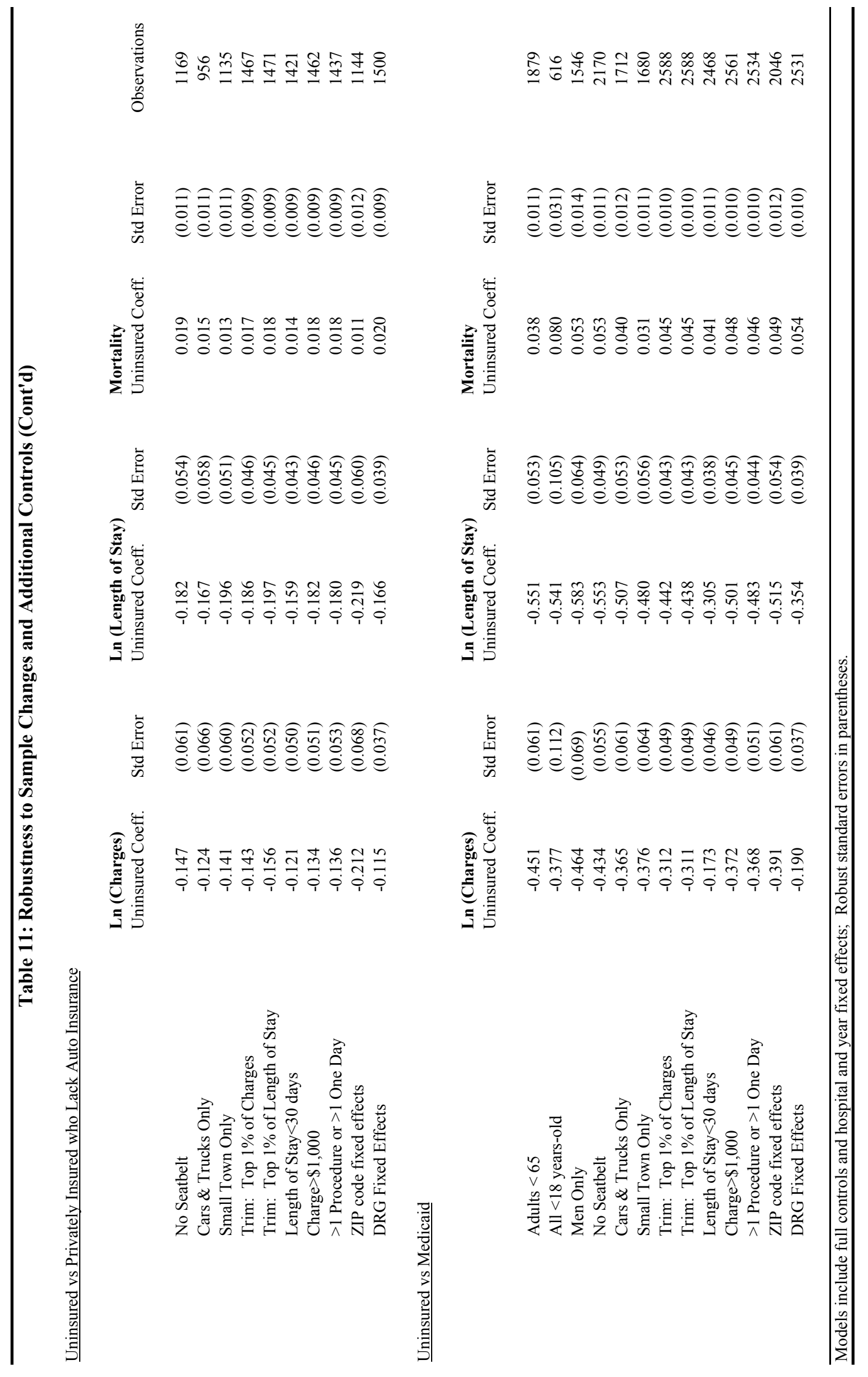


Table A1: Full Treatment Results

Ln(Total Charges)

uninsured

age $<16$

age $>=16 \&<25$

age $>=25 \&<35$

age $>=35 \&<45$

female

car

truck

motorcycle

car passenger

restraint seat belt/child seat

severe vehicle damage

trapped

angle collision

sideswipe collision

other collision

wet pavement

rural street

urban highway

rural highway

urban interstate

rural interstate

small town $<25,000$

medium town $<250,000$

nervous system

respiratory

musculoskeletal \& tissue

skin, tissue, \& breast

multiple significant trauma

Continued on Next Page

$\underline{\text { Ln(Length of Stay) }}$

\begin{tabular}{|c|c|c|c|c|c|}
\hline $\begin{array}{l}\text { Main } \\
\text { (1) }\end{array}$ & $\begin{array}{c}\text { vs. No Auto Ins. } \\
\text { (2) }\end{array}$ & $\begin{array}{c}\text { vs. Medicaid } \\
\text { (3) }\end{array}$ & $\begin{array}{l}\text { Main } \\
(4)\end{array}$ & $\begin{array}{l}\text { vs. No Auto Ins. } \\
\text { (5) }\end{array}$ & $\begin{array}{c}\text { vs. Medicaid } \\
\text { (6) }\end{array}$ \\
\hline-0.137 & -0.148 & -0.370 & -0.170 & -0.190 & -0.497 \\
\hline$(0.025)$ & $(0.053)$ & $(0.050)$ & $(0.022)$ & (0.046) & $(0.044)$ \\
\hline-0.268 & -0.228 & -0.471 & -0.195 & -0.030 & -0.408 \\
\hline$(0.041)$ & $(0.263)$ & $(0.093)$ & $(0.036)$ & $(0.252)$ & $(0.084)$ \\
\hline-0.169 & -0.088 & -0.212 & -0.197 & -0.219 & -0.204 \\
\hline$(0.029)$ & $(0.086)$ & $(0.073)$ & $(0.025)$ & $(0.077)$ & $(0.065)$ \\
\hline-0.115 & -0.008 & -0.139 & -0.150 & -0.163 & -0.135 \\
\hline$(0.030)$ & $(0.086)$ & $(0.075)$ & $(0.025)$ & $(0.077)$ & $(0.067)$ \\
\hline-0.080 & 0.026 & -0.133 & -0.084 & -0.094 & -0.140 \\
\hline$(0.031)$ & $(0.095)$ & $(0.081)$ & $(0.026)$ & $(0.082)$ & $(0.073)$ \\
\hline-0.044 & -0.005 & -0.096 & 0.039 & 0.046 & -0.020 \\
\hline$(0.020)$ & $(0.059)$ & $(0.045)$ & $(0.017)$ & $(0.053)$ & $(0.040)$ \\
\hline-0.162 & -0.295 & -0.268 & -0.135 & -0.245 & -0.232 \\
\hline$(0.046)$ & $(0.092)$ & $(0.087)$ & $(0.040)$ & $(0.080)$ & $(0.077)$ \\
\hline-0.130 & -0.226 & -0.231 & -0.113 & -0.224 & -0.249 \\
\hline$(0.050)$ & (0.112) & (0.104) & $(0.044)$ & (0.109) & (0.091) \\
\hline 0.023 & 0.000 & -0.051 & -0.017 & 0.000 & -0.101 \\
\hline$(0.040)$ & $(0.000)$ & $(0.084)$ & $(0.034)$ & $(0.000)$ & $(0.075)$ \\
\hline 0.015 & 0.000 & -0.021 & 0.023 & 0.000 & -0.018 \\
\hline$(0.024)$ & $(0.000)$ & $(0.050)$ & $(0.021)$ & $(0.000)$ & $(0.044)$ \\
\hline-0.161 & -0.177 & -0.198 & -0.090 & -0.070 & -0.139 \\
\hline$(0.023)$ & $(0.070)$ & $(0.059)$ & $(0.020)$ & $(0.061)$ & $(0.051)$ \\
\hline 0.052 & 0.267 & 0.137 & 0.025 & 0.170 & 0.102 \\
\hline$(0.030)$ & $(0.082)$ & (0.061) & $(0.025)$ & $(0.070)$ & $(0.053)$ \\
\hline 0.222 & 0.199 & 0.249 & 0.118 & 0.169 & 0.169 \\
\hline$(0.027)$ & $(0.079)$ & $(0.061)$ & $(0.024)$ & $(0.071)$ & $(0.056)$ \\
\hline-0.262 & -0.156 & -0.143 & -0.141 & -0.067 & -0.074 \\
\hline$(0.031)$ & $(0.085)$ & $(0.075)$ & $(0.027)$ & $(0.078)$ & $(0.068)$ \\
\hline-0.100 & 0.117 & -0.038 & -0.062 & 0.088 & 0.023 \\
\hline$(0.050)$ & $(0.135)$ & $(0.122)$ & $(0.042)$ & $(0.121)$ & $(0.100)$ \\
\hline-0.207 & -0.104 & -0.085 & -0.119 & -0.051 & -0.035 \\
\hline$(0.029)$ & (0.077) & $(0.069)$ & $(0.026)$ & $(0.072)$ & $(0.064)$ \\
\hline 0.003 & 0.215 & -0.008 & 0.009 & 0.184 & 0.016 \\
\hline$(0.022)$ & $(0.071)$ & $(0.050)$ & $(0.019)$ & $(0.062)$ & $(0.045)$ \\
\hline 0.172 & 0.028 & 0.345 & 0.088 & -0.011 & 0.232 \\
\hline$(0.040)$ & $(0.105)$ & $(0.088)$ & $(0.034)$ & $(0.091)$ & $(0.078)$ \\
\hline 0.001 & -0.114 & 0.108 & 0.002 & -0.057 & -0.001 \\
\hline$(0.037)$ & $(0.109)$ & $(0.080)$ & $(0.032)$ & $(0.093)$ & $(0.073)$ \\
\hline 0.173 & -0.006 & 0.294 & 0.090 & -0.005 & 0.208 \\
\hline$(0.041)$ & $(0.109)$ & $(0.090)$ & $(0.035)$ & $(0.092)$ & $(0.080)$ \\
\hline 0.055 & 0.566 & 0.177 & 0.011 & 0.501 & -0.126 \\
\hline$(0.084)$ & $(0.250)$ & $(0.166)$ & $(0.069)$ & $(0.200)$ & $(0.194)$ \\
\hline 0.153 & -0.366 & 0.098 & 0.064 & -0.217 & 0.013 \\
\hline$(0.066)$ & $(0.186)$ & $(0.160)$ & $(0.056)$ & $(0.177)$ & $(0.140)$ \\
\hline 0.167 & 0.219 & 0.125 & 0.142 & 0.219 & 0.073 \\
\hline$(0.062)$ & $(0.173)$ & $(0.132)$ & $(0.053)$ & $(0.141)$ & (0.118) \\
\hline 0.159 & 0.055 & 0.209 & 0.104 & 0.068 & 0.142 \\
\hline$(0.059)$ & $(0.157)$ & $(0.117)$ & $(0.051)$ & $(0.139)$ & $(0.106)$ \\
\hline 0.120 & 0.043 & 0.184 & 0.195 & 0.147 & 0.190 \\
\hline$(0.038)$ & $(0.100)$ & $(0.074)$ & (0.031) & $(0.083)$ & $(0.063)$ \\
\hline 0.020 & 0.074 & 0.212 & 0.188 & 0.249 & 0.314 \\
\hline$(0.043)$ & $(0.128)$ & $(0.096)$ & $(0.034)$ & $(0.105)$ & $(0.080)$ \\
\hline 0.184 & 0.142 & 0.172 & 0.254 & 0.219 & 0.283 \\
\hline$(0.031)$ & $(0.080)$ & $(0.063)$ & $(0.025)$ & $(0.068)$ & $(0.054)$ \\
\hline-0.449 & -0.375 & -0.384 & -0.295 & -0.184 & -0.269 \\
\hline$(0.038)$ & $(0.106)$ & (0.081) & $(0.030)$ & $(0.089)$ & $(0.066)$ \\
\hline 0.982 & 0.845 & 1.039 & 0.706 & 0.606 & 0.761 \\
\hline$(0.034)$ & (0.090) & $(0.070)$ & $(0.030)$ & $(0.084)$ & (0.067) \\
\hline
\end{tabular}

Models include hospital and year fixed effects and indicators for day of the week, hour of the day, and vehicle model year.

Missing vehicle and ZIP code data have been filled with sample means and indicators for missing values are included.

Omitted categories are age $>45$, head-on collision; other vehicle, bicycle \& pedestrians; urban street; large town;

smallest vehicle engines, weight, and MSRP; fraction white; fraction with college education; and other major diagnosis.

Robust standard errors in parentheses; 


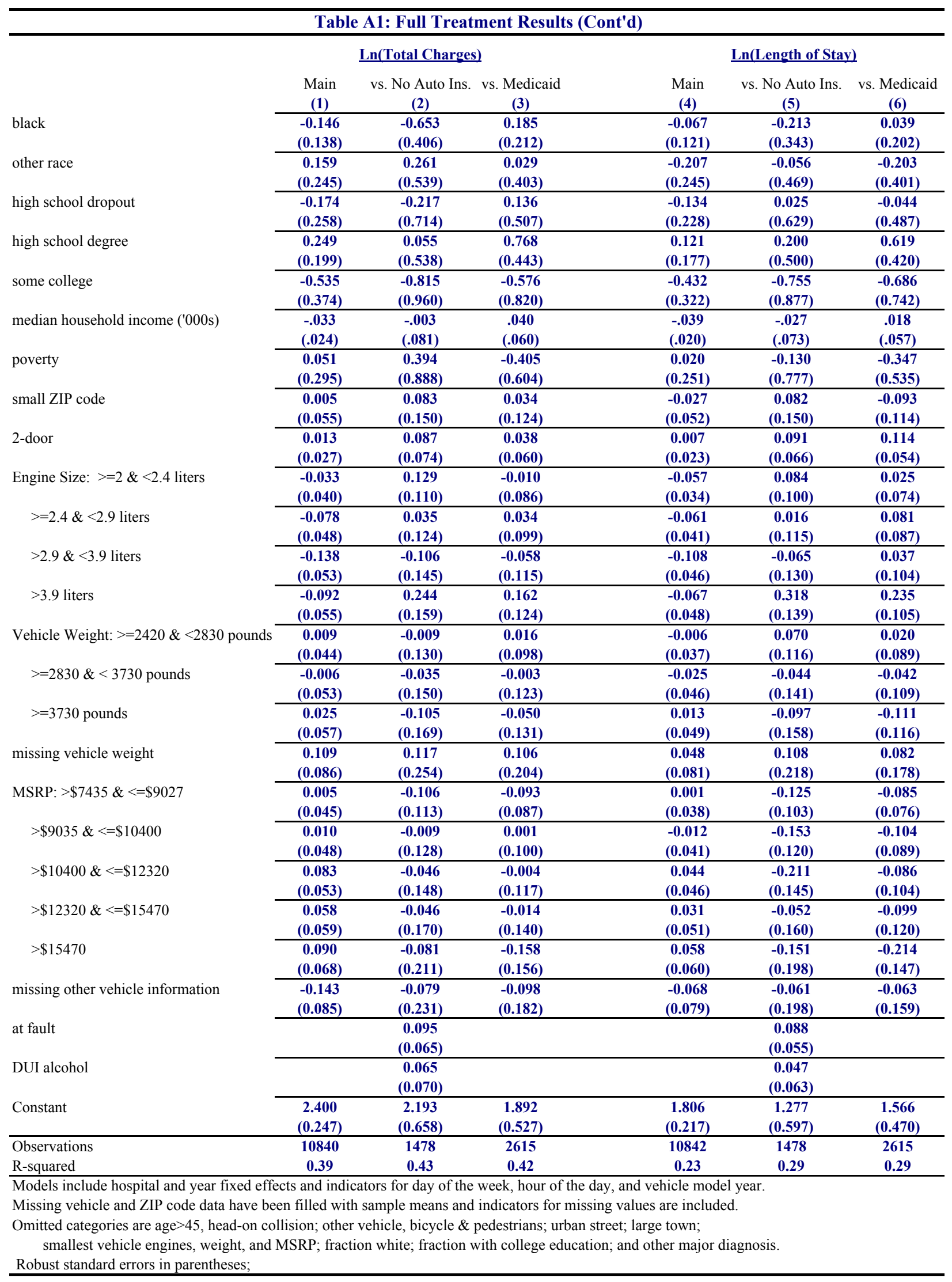


Table A2: Mortality Results

uninsured

age $<16$

age $>=16 \&<25$

age $>=25 \&<35$

age $>=35 \&<45$

female

car

truck

motorcycle

car passenger

restraint seat belt/child seat

severe vehicle damage

trapped

angle collision

sideswipe collision

other collision

wet pavement

rural street

urban highway

rural highway

urban interstate

rural interstate

small town $<25,000$

medium town $<250,000$

nervous system

respiratory

musculoskeletal \& tissue

skin, tissue, \& breast

multiple significant trauma

Continued on Next Page
Fatal

Main vs. No Auto Ins. vs. Medicaid

\begin{tabular}{ccc}
$(1)$ & $(2)$ & $(3)$ \\
\hline 0.015 & 0.017 & 0.047 \\
$(0.006)$ & $(0.009)$ & $(0.010)$ \\
\hline-0.006 & $-\mathbf{0 . 0 2 1}$ & $-\mathbf{0 . 0 0 3}$ \\
$(0.009)$ & $(0.020)$ & $(0.020)$ \\
\hline-0.013 & 0.013 & -0.013 \\
$(0.006)$ & $(0.015)$ & $(0.016)$
\end{tabular}

\begin{tabular}{ccc}
$(0.006)$ & $(0.015)$ & $(0.016)$ \\
\hline-0.015 & 0.005 & -0.020
\end{tabular}

\begin{tabular}{lll}
$(0.006)$ & $(0.015)$ & $(0.015)$ \\
\hline
\end{tabular}

$\begin{array}{lll}-0.008 & -0.002 & -0.009\end{array}$

$\begin{array}{lll}(0.006) & (0.016) & (0.017)\end{array}$

$\begin{array}{lll}0.001 & 0.013 & 0.011\end{array}$

$\begin{array}{rrr}(0.004) & (0.011) & (0.009)\end{array}$

$\begin{array}{lll}-0.012 & 0.005 & 0.002\end{array}$

$\begin{array}{lll}(0.010) & (0.015) & (0.019)\end{array}$

$\begin{array}{lcc}-0.009 & 0.018 & 0.006 \\ (0.011) & (0.023) & (0.024)\end{array}$

$\begin{array}{lcc}(0.011) & (0.023) & (0.024) \\ -0.011 & 0.000 & -0.019\end{array}$

$\begin{array}{lll}(0.008) & (0.000) & (0.017)\end{array}$

$\mathbf{- 0 . 0 0 3} \quad \mathbf{0 . 0 0 0} \quad \mathbf{- 0 . 0 0 1}$

$\begin{array}{lll}(0.005) & (0.000) & (0.009)\end{array}$

$\begin{array}{lll}-0.007 & -0.008 & 0.000\end{array}$

$\begin{array}{lll}(0.004) & (0.012) & (0.010)\end{array}$

$0.005 \quad-0.003 \quad-0.010$

$\begin{array}{lll}(0.006) & (0.014) & (0.012)\end{array}$

$0.013 \quad-\mathbf{0 . 0 2 0} \quad-\mathbf{0 . 0 0 7}$

$\begin{array}{lll}(0.006) & (0.012) & (0.012)\end{array}$

$\begin{array}{lll}0.005 & -0.000 & 0.005\end{array}$

$\begin{array}{lll}(0.006) & (0.016) & (0.015)\end{array}$

$\begin{array}{lll}0.013 & 0.004 & 0.021\end{array}$

$\begin{array}{lll}(0.010) & (0.024) & (0.022)\end{array}$

$0.009 \quad-\mathbf{0 . 0 0 1} \quad 0.006$

$\begin{array}{lll}(0.006) & (0.014) & (0.014)\end{array}$

$\begin{array}{lcc}0.005 & 0.004 & 0.012\end{array}$

$\begin{array}{lll}(0.005) & (0.012) & (0.010)\end{array}$

$\begin{array}{lll}0.009 & 0.030 & 0.027\end{array}$

$\begin{array}{lll}(0.007) & (0.016) & (0.014)\end{array}$

$\begin{array}{lll}0.013 & -0.017 & 0.027\end{array}$

$\begin{array}{ccc}(0.008) & (0.013) & (0.016)\end{array}$

$\begin{array}{lll}0.006 & 0.020 & 0.019\end{array}$

$\begin{array}{lll}(0.008) & (0.015) & (0.014)\end{array}$

$\begin{array}{lll}-0.011 & -0.018 & 0.025\end{array}$

$\begin{array}{lll}(0.015) & (0.023) & (0.053)\end{array}$

$\begin{array}{llr}0.013 & 0.039 & 0.025\end{array}$

$\begin{array}{lll}(0.013) & (0.031) & (0.028)\end{array}$

$\begin{array}{lll}-0.015 & -0.025 & -0.055\end{array}$

$\begin{array}{lll}(0.012) & (0.025) & (0.025)\end{array}$

$\begin{array}{lll}-0.010 & 0.005 & -0.035\end{array}$

$\begin{array}{lll}(0.012) & (0.027) & (0.025)\end{array}$

$\begin{array}{lll}0.027 & 0.041 & 0.049\end{array}$

$\begin{array}{lll}(0.007) & (0.016) & (0.013)\end{array}$

$\begin{array}{lll}-0.007 & -0.007 & 0.003\end{array}$

\begin{tabular}{llc}
-0.007 & -0.007 & 0.003 \\
$(0.007)$ & $(0.013)$ & $(0.015)$ \\
\hline
\end{tabular}

$\begin{array}{lll}-0.022 & -0.005 & -0.020\end{array}$

$\begin{array}{lll}(0.005) & (0.009) & (0.009)\end{array}$

$\mathbf{- 0 . 0 2 0} \quad-\mathbf{0 . 0 1 3} \quad-\mathbf{- 0 . 0 0 9}$

$\begin{array}{lll}(0.005) & (0.011) & (0.010)\end{array}$

$\begin{array}{lcc}0.076 & 0.069 & 0.093\end{array}$

$\begin{array}{lll}(0.008) & (0.019) & (0.018)\end{array}$

Models include hospital and year fixed effects and indicators for day of the week, hour of the day, and vehicle model yea: Missing vehicle and ZIP code data have been filled with sample means and indicators for missing values are included.

Omitted categories are age $>45$, head-on collision; other vehicle, bicycle \& pedestrians; urban street; large town;

smallest vehicle engines, weight, and MSRP; fraction white; fraction with college education; and other major diagnc

Robust standard errors in parentheses; 
Table A2: Mortality Results (Cont'd)

black

other race

high school dropout

high school degree

some college

median household income (000's)

poverty

small ZIP code

2-door

Engine Size: $>=2 \&<2.4$ liters

$$
\begin{aligned}
& >=2.4 \&<2.9 \text { liters } \\
& >2.9 \&<3.9 \text { liters } \\
& >3.9 \text { liters }
\end{aligned}
$$

Vehicle Weight: $>=2420 \&<2830$ pounds

$$
\begin{aligned}
& >=2830 \&<3730 \text { pounds } \\
& >=3730 \text { pounds }
\end{aligned}
$$

missing vehicle weight

MSRP: > $\$ 7435 \&<=\$ 9027$

$$
\begin{aligned}
& >\$ 9035 \&<=\$ 10400 \\
& >\$ 10400 \&<=\$ 12320 \\
& >\$ 12320 \&<=\$ 15470
\end{aligned}
$$$$
>\$ 15470
$$

missing other vehicle information

at fault

DUI alcohol

Constant

Observations

R-squared

Models include hospital and year fixed effects and indicators for day of the week, hour of the day, and vehicle model year. Missing vehicle and ZIP code data have been filled with sample means and indicators for missing values are included. Omitted categories are age $>45$, head-on collision; other vehicle, bicycle \& pedestrians; urban street; large town;

smallest vehicle engines, weight, and MSRP; fraction white; fraction with college education; and other major diagnosi Robust standard errors in parentheses;

\begin{tabular}{ccc} 
Main & vs. No Auto Ins. & vs. Medicaid \\
$(\mathbf{1})$ & $(\mathbf{2})$ & $\mathbf{( 3 )}$ \\
\hline $\mathbf{0 . 0 0 6}$ & $\mathbf{0 . 0 5 3}$ & $\mathbf{- 0 . 0 3 6}$ \\
$\mathbf{( 0 . 0 2 8 )}$ & $\mathbf{( 0 . 0 6 1 )}$ & $\mathbf{( 0 . 0 4 5 )}$ \\
\hline $\mathbf{0 . 1 3 3}$ & $\mathbf{- 0 . 0 4 2}$ & $\mathbf{- 0 . 0 0 6}$ \\
$(\mathbf{0 . 0 7 2 )}$ & $\mathbf{( 0 . 0 7 5 )}$ & $\mathbf{( 0 . 0 6 4 )}$ \\
\hline $\mathbf{0 . 0 6 8}$ & $\mathbf{- 0 . 0 8 5}$ & $\mathbf{0 . 1 7 7}$ \\
$(\mathbf{0 . 0 5 3 )}$ & $(\mathbf{0 . 1 2 6 )}$ & $\mathbf{( 0 . 1 2 0 )}$ \\
\hline
\end{tabular}

\begin{tabular}{ccc}
\hline 0.010 & 0.031 & -0.095 \\
$(0.042)$ & $(0.096)$ & $(0.103)$ \\
\hline-0.011 & 0.054 & 0.241 \\
$(0.074)$ & $(0.194)$ & $(0.160)$
\end{tabular}

\begin{tabular}{ccc}
$(0.074)$ & $(0.194)$ & $(0.166)$ \\
\hline 0.006 & 0.007 & -0.007
\end{tabular}

$\begin{array}{lll}(.005) & (.014) & \mathbf{( . 0 1 2 )}\end{array}$

$\begin{array}{lll}\mathbf{- 0 . 0 1 9} & \mathbf{0 . 1 0 0} & \mathbf{- 0 . 0 2 4}\end{array}$

$\begin{array}{lll}(0.056) & (0.142) & (0.136)\end{array}$

$0.010 \quad-0.025 \quad 0.064$

$\begin{array}{lll}(0.013) & (0.041) & (0.036)\end{array}$

\begin{tabular}{ccc}
\hline-0.001 & -0.018 & -0.030 \\
$(0.005)$ & $(0.015)$ & $(0.011)$
\end{tabular}

\begin{tabular}{ccc}
\hline 0.003 & $-\mathbf{0 . 0 0 8}$ & $-\mathbf{0 . 0 1 4}$ \\
$(0.007)$ & $(0.016)$ & $(0.015)$ \\
\hline-0.004 & 0.037 & -0.006
\end{tabular}

$\begin{array}{lll}(0.009) & (0.023) & (0.020)\end{array}$

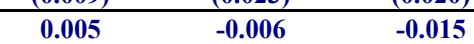

$\begin{array}{lll}(0.011) & (0.024) & (0.023)\end{array}$

$\mathbf{- 0 . 0 0 2} \quad-\mathbf{0 . 0 1 7} \quad \mathbf{- 0 . 0 4 2}$

$\begin{array}{lll}(0.011) & (0.028) & (0.023)\end{array}$

$0.006 \quad-0.020 \quad-0.014$

\begin{tabular}{ccc}
$(0.009)$ & $(0.023)$ & $(0.019)$ \\
\hline 0.013 & 0.019 & -0.016
\end{tabular}

$\begin{array}{lll}(0.011) & (0.029) & (0.023)\end{array}$

$\begin{array}{lll}0.002 & 0.012 & 0.021\end{array}$

$\begin{array}{lll}(0.011) & (0.032) & (0.025)\end{array}$

$\begin{array}{lll}0.019 & 0.024 & 0.008\end{array}$

\begin{tabular}{ccc}
$(0.017)$ & $(0.067)$ & $(0.044)$ \\
\hline 0.004 & 0.029 & 0.037
\end{tabular}

$\begin{array}{ccc}0.004 & & 0.037 \\ (0.009) & (0.023) & (0.017)\end{array}$

$\begin{array}{lll}0.003 & 0.003 & 0.036\end{array}$

$\begin{array}{lll}(0.010) & (0.026) & (0.022)\end{array}$

$\begin{array}{lll}0.007 & 0.046 & 0.039\end{array}$

$\begin{array}{lll}(0.011) & (0.033) & (0.023)\end{array}$

$\begin{array}{lll}-0.001 & -0.027 & 0.033\end{array}$

\begin{tabular}{lll}
$(0.012)$ & $(0.029)$ & $(0.028)$ \\
\hline
\end{tabular}

$\begin{array}{llr}-0.010 & -0.022 & 0.034 \\ (0.014) & (0.038) & (0.033)\end{array}$

\begin{tabular}{ccc}
$(0.014)$ & $(0.038)$ & $(0.033)$ \\
\hline-0.015 & -0.027 & 0.010 \\
$(0.017)$ & $(0.059)$ & $(0.040)$ \\
\hline
\end{tabular}

\begin{tabular}{ccc}
$(0.017)$ & $(0.040)$ \\
\hline 0.007 \\
$(0.010)$ \\
\hline
\end{tabular}

\begin{tabular}{ccc}
\hline & 0.005 & \\
& $(0.012)$ & \\
\hline 0.002 & -0.070 & -0.015 \\
$(0.049)$ & $(0.120)$ & $(0.119)$ \\
\hline
\end{tabular}

$10842 \quad 1478 \quad 2615$

Fatal 